\title{
Patología laboral sensibilizante, respiratoria y cutánea en la industria alimentaria
}

\section{Pathology labor sensitising, respiratory and skin in the food industry}

\author{
Cedeño Gabriel, Karly Paola ${ }^{1,4}$; Rubial Carvajal, Gabriela ${ }^{2,5 ;}$ Ruiz Almirón, Carmen ${ }^{3,4}$ \\ 1. Hospital de Cabueñes, Gijón. España. \\ 2. Hospital Infanta Leonor, Madrid, España. \\ 3. Ibermutuamur, Oviedo. España. \\ 4. Unidad Docente de Medicina del Trabajo del Principado de Asturias, Gijón. España. \\ 5. Unidad Docente de Medicina del Trabajo de la Comunidad de Madrid, Madrid. España.
}

Recibido: 23-01-14

Aceptado: 17-07-14

\section{Correspondencia}

Carmen Ruiz Almirón

Ibermutuamur, Oviedo. España.

Correo electrónico: cammen@hotmail.com

Resumen

La introducción de nuevas sustancias en la industria alimentaria ocasiona nuevas «sensibilizaciones» a multitud de productos como son materias primas de aditivos alimentarios y productos intermedios. Existen factores tanto individuales (atopía, tabaquismo, rinitis) como industriales (niveles de exposición, poder de sensibilización de los alérgenos, "trabajo húmedo") asociados a un mayor riesgo de presentación de asma y dermatitis de contacto ocupacional (irritativa y alérgica). La importancia desde el punto de vista del número de casos notificados, hace necesario profundizar en el conocimiento y evidencia científica existente en cuanto a la epidemiologia e historia natural de la enfermedad profesional por hipersensibilidad. Con el objetivo de determinar la evidencia científica existente sobre la asociación entre las condiciones de trabajo y las enfermedades pulmonares y dermatosis en la industria alimentaria, se realizó un análisis sistemático de la producción científica identificada entre 2007-2012, en las principales bases de datos bibliográficas: PubMed, Scielo, Embase, Scopus, Lilacs, www.ilo.org/cisdocdatabase. Un total de 23 artículos cumplieron los criterios de inclusión. Los resultados permiten concluir que la prevalencia por hipersensibilidad varia en función de la actividad y del agente sensibilizante entre $7 \%$ y un $38,7 \%$ con un nivel de evidencia entre $2++$ y 3. Dentro de las dermatosis ocupacionales, la dermatitis de contacto irritativa sigue siendo más prevalente que la dermatitis de contacto alérgica. La dermatitis de contacto proteínica es un trastorno frecuente en manipuladores de alimentos y debe considerarse una entidad clínica aparte. La atopía es un factor de riesgo para el desarrollo de clínica respiratoria y cutánea. No se identificaron en la literatura nuevos test diagnósticos.

Med Segur Trab (Internet) 2014; 60 (236) 536-565

Palabras clave: Industria alimentaria, Dermatitis ocupacional, Asma, Asma ocupacional, Exposición ocupacional, Alérgenos laborales, Enfermedad profesional.

Abstract

The introduction of new substances in the food industry brings new "sensitization" a multitude of products such as food additives raw materials and intermediates. There are both individual factors (atopy, smoking, rhinitis) and industrial (levels of exposure, sensitization to allergens, "wet work") associated with an increased risk of asthma and presentation of occupational contact dermatitis (irritant and allergic). The 
importance from the point of view of the number of reported cases is necessary to deepen the existing knowledge and scientific evidence regarding the epidemiology and natural history of occupational disease hypersensitivity. With the aim of ascertaining the scientific evidence concerning the association between working conditions and pulmonary diseases and dermatoses in the food industry, a systematic analysis of the scientific production from 2007-2012, on the main bibliographic databases, was performed: PubMed, SciELO, EMBASE, Scopus, Lilacs, www.ilo.org / cisdocdatabase. A total of 23 articles met the inclusion criteria. The results suggest that the prevalence of hypersensitivity varies depending of the activity and sensitizing agent between $7 \%$ and $38.7 \%$ with a level of evidence between $2++$ and 3 . Within occupational dermatoses, irritant contact dermatitis is still more prevalent than allergic contact dermatitis. Protein contact dermatitis is a common disorder in food handlers and should be considered a separate clinical entity. Atopy is a risk factor for the development of respiratory and skin symptoms. Were not identified in the literature new diagnostic test.

Med Segur Trab (Internet) 2014; 60 (236) 536-565

Keywords: Food industry, Dermatitis occupational, Asthma, Asthma occupational, Occupational exposure, Occupational allergens, Occupational disease. 


\section{INTRODUCCIÓN}

El riesgo que supone para el trabajador la exposición laboral a ciertas sustancias es conocido desde la Antigüedad, sin embargo no es hasta el siglo XVI, con las observaciones de Agrícola y Paracelso, cuando se despierta cierto interés por la posible relación entre el trabajo y la enfermedad ${ }^{1}$.

Con la introducción de un elevado número de sustancias químicas en la industria estamos siendo testigos de la aparición de nuevas «sensibilizaciones» a multitud de productos. Adecuándonos a la legislación laboral española (Artículo 116 de la Ley General de Seguridad Social de 1994) ${ }^{2}$ podemos definir la alergia laboral, o bien la patología laboral "sensibilizante», como todas aquellas enfermedades de mecanismo inmunológico, que tienen su origen a consecuencia del trabajo efectuado por cuenta ajena, en las actividades que se especifiquen en el cuadro aprobado por las disposiciones de aplicación y desarrollo de esta Ley, y que estén provocadas por la acción de los elementos o instancias que en dicho cuadro se indiquen para cada caso. Dentro de éste grupo nos encontramos con enfermedades respiratorias y cutáneas, ambas presentes en distintos sectores de la Industria Alimentaria 1,3,4.

En el siglo XVIII, Bernardino Ramazzini (1633-1714) en su obra Tratado de las enfermedades de los artesanos (De morbis artificum diatriba, $1 .^{a}$ ed., Módena, $1700 ;{ }^{a} .^{a}$ ed., Padua, 1713) describe los primeros casos de asma bronquial en trabajadores de molinos y limpiadores de grano secundarios a la inhalación de polvos de cereales ${ }^{1,4}$. La enfermedad pulmonar ocupacional (EPO) define la afectación bronquial, alveolointersticial y/o pleural secundaria a la exposición del sujeto a materia particulada, vapores, gases o humos en su ambiente de trabajo ${ }^{1}$.

Hay dos formas de asma ocupacional: asma alérgico, caracterizado por un periodo de latencia y asma inducido por irritantes, caracterizado por la rápida aparición de asma tras una exposición única o múltiple a altas concentraciones de compuestos irritativos ${ }^{5}$. Según su mecanismo patogénico se distinguen dos entidades de asma ocupacional por hipersensibilidad (o inmunológico): a) Asma ocupacional inmunológico causado por sustancias de alto peso molecular, dónde interviene un mecanismo inmunológico mediado por IgE y b) Asma ocupacional inmunológico causado por sustancias de bajo peso molecular, sin intervenir en general un mecanismo IgE mediado, sino posiblemente un mecanismo de hipersensibilidad de tipo celular o tardío ${ }^{1,4,5}$.

Las neumonitis por hipersensibilidad (NH), también conocidas como alveolitis alérgicas extrínsecas (AAE), constituyen un grupo de enfermedades inflamatorias del pulmón que afectan preferentemente a las vías respiratorias más periféricas y que son inducidas inmunológicamente (linfocitos $\mathrm{T}$ principalmente) tras la inhalación repetida de partículas orgánicas o compuestos químicos de bajo peso molecular ${ }^{1,4}$.

En los últimos años han aparecido nuevos antígenos dentro de la industria alimentaria. Cartier y cols ${ }^{6}$ describen una serie de alérgenos, aditivos alimentarios y contaminantes capaces de ocasionar asma ocupacional. La harina de caléndula es muy utilizada como aditivo alimentario (colorante alimentario) de las aves de corral. LluchPérez y cols., en 2009, describen el primer caso de alergia ocupacional (rinitis y asma) por este aditivo5.

El asma ocupacional en la industria del pescado suele deberse a la exposición a crustáceos, aunque los moluscos y el pescado también pueden estar implicados; hay descrito un caso de asma ocupacional por alérgenos de pulpo en un trabajador de procesamiento de marisco; tres casos de asma y rinoconjuntivitis (RC) por sensibilización al rodaballo y asma ocupacional causada por la exposición a Anisakis simplex en el procesamiento del pescado5. Recientemente se han publicado trabajos sobre asma profesional en una compañía de fabricación de malta; asma por exposición a polvo de arroz en el entorno laboral; y un caso de RC y asma secundario a polvo seco de achicoria ${ }^{5}$. También existen parásitos y artrópodos capaces de desarrollar éste tipo de patología; 
Chrysonilia sitophila en la industria del café y Penicillium nalgiovensis en charcuteros semi-industriales 5 .

Existen factores tanto individuales como industriales asociados con la aparición de AO; la atopía es el factor de riesgo más importante en el desarrollo de ésta. La atopía se relaciona con un incremento del riesgo de desarrollo de asma laboral en trabajadores expuestos a harina (panaderos), enzimas y cangrejos. El hábito tabáquico se ha asociado con el riesgo aumentado de $\mathrm{AO}$ en trabajadores procesadores del cangrejo de las nieves -y salmón- y con la sensibilización en profesionales expuestos a cangrejo, gambas, calamar, sardina, anchoa, granos de café verde y harinas. La aparición de rinitis a menudo precede al asma y es probablemente un factor de riesgo para el desarrollo de AO, pero no el asma preexistente como tal, a menos que el individuo sea atópico. Dentro de los factores industriales que se asocian con un riesgo mayor de AO están los niveles de exposición y el poder de sensibilización de los alérgenos alimentarios ${ }^{6}$.

Las EPO constituyen un tema de enorme interés por ser causa importante de baja laboral, incapacidad y muerte ${ }^{1}$. En la actualidad el AO constituye la enfermedad respiratoria de causa profesional más frecuente en la mayoría de los países industrializados.

El asma de origen laboral tiene una gran importancia por sus implicaciones clínicas, socio-económicas y médico-legales, por lo que el diagnóstico precoz es fundamental. Los datos disponibles indican que alrededor de un 10-15\% de todos los casos de asma tienen un origen laboral ${ }^{4}$.

Aunque previamente a la Revolución Industrial del siglo XIX se había hecho mención del daño que ejercían algunas profesiones sobre la piel (Ellemborg y Agrícola, Paracelso, Ramazzini), es a partir de ésta época cuando se empieza a prestar una importancia decisiva a este campo de la medicina ${ }^{1}$.

Las dermatosis profesionales (DP) se clasifican según el agente que las puede provocar, de tal manera que tenemos: a) mecánicas; b) físicas; c) químicas; d) vegetales; e) biológicas, y f) otras formas. Dentro de las dermatosis alérgicas ocupacionales podemos destacar el eccema alérgico de contacto profesional (EACP) o dermatitis de contacto alérgica (DCA), la dermatitis y urticaria proteínica de contacto, la urticaria de contacto y las dermatosis alérgicas aerotransportadas ${ }^{1}$. Fuera de las dermatosis de causa alérgica se encuentra la dermatitis de contacto irritativa (DCI) presentación muy frecuente . $^{4}$

Las afecciones dermatológicas representan una elevada proporción de las enfermedades ocupacionales, suponiendo aproximadamente el $20 \%$ de todas ellas, con una frecuencia similar a las enfermedades mentales y superadas solamente por la patología de origen músculo-esquelético y articular ${ }^{4}$. Aproximadamente el 95\% de las dermatosis de origen laboral corresponden a dermatitis de contacto, siendo la mayor parte de ellas de origen irritativo (aproximadamente un $80 \%)^{7}$ aunque, con el uso más generalizado de las pruebas epicutáneas en el diagnóstico, quizás una proporción elevada de éstos eccemas sean realmente alérgicos ${ }^{4}$

En la industria alimentaria, los alérgenos que con mayor frecuencia se relacionan con las dermatosis alérgicas son los siguientes ${ }^{1}$ : Componentes de las gomas (guantes), Proteínas animales (carnes y pescados), vegetales y frutas.

La profesión es un factor clave en el desarrollo de dermatitis de contacto, representando las DCO en torno al 90- 95\% de todas las dermatitis de contacto. Entre otras ocupaciones, las DCO son comunes en los agricultores, chefs y manipuladores de alimentos; "el trabajo húmedo» es el factor exógeno más frecuentemente implicado en la DCO, afectando, entre otros, a profesiones como panaderos, cocineros, y empleados en la industria alimentaria. En éstas ocupaciones también es habitual el contacto frecuente con el agua, causa importante de DCI. La dermatitis atópica (DA) está asociada con una tasa mayor de DCA y DCI. Muchos estudios han mostrado de forma repetida que la DA es el factor de riesgo más importante en el desarrollo del eccema de manos; sin embargo la asociación entre DA y DCA es controvertida y la relación entre las dos aún no está 
clara, ya que mientras el estado atópico incrementa el riesgo de aparición de DCA, no hay evidencias que sugieran que la DCA es más prevalente entre pacientes atópicos?

Gran parte de las enfermedades profesionales de naturaleza alérgica son notificadas como enfermedades causadas por agentes químicos (isocianatos, disolventes orgánicos, etc.), no registrándose la naturaleza del cuadro que producen (intoxicación, nefropatía o neumopatía), quedando, por tanto, diluidas en el conjunto de enfermedades por agentes químicos. A este hecho es necesario añadir la dificultad de nuestro sistema sanitario, tanto en el ámbito de atención primaria como especializada, para identificar cuadros profesionales de origen alérgico, por lo que éstos quedan entre la maraña de la enfermedad común, lo que implica en el mejor de los casos una tardanza en la realización del diagnóstico etiológico del proceso ${ }^{3}$.

El reconocimiento de la enfermedad por hipersensibilidad en el cuadro de enfermedades profesionales (RD 1299/2006) ${ }^{8}$ y su importancia desde el punto de vista del número de casos notificados, hace necesario profundizar y determinar la evidencia científica existente sobre la asociación entre las condiciones de trabajo y las enfermedades pulmonares y dermatosis en la industria alimentaria, objetivo de este trabajo. Que también trata de responder a: Conocer la prevalencia e incidencia de la patología sensibilizante dentro de la industria alimentaria así como los compuestos alergénicos presentes en los distintos puestos de trabajo de dicha industria. Identificar las técnicas empleadas en el diagnóstico de las enfermedades alérgicas tanto respiratorias como cutáneas. Conocer el impacto de la enfermedad en términos de incapacidad laboral y su tipo e Identificar los factores de exposición y condiciones de vulnerabilidad para la enfermedad por hipersensibilidad.

\section{MATERIAL Y MÉTODOS}

Se realiza una revisión sistemática de la literatura científica identificada mediante el empleo de términos de Thesaurus y Medical Subject Heading (MeSH), para la búsqueda en MEDLINE vía PubMed, SCOPUS, OSH-UPDATE y Sciencedirect, IBECS y IBSST. Para la búsqueda en otras bases de datos se utilizaron otros descriptores «no MeSH» combinados o no con términos «MeSH».

Las ecuaciones de búsqueda se desarrollaron para su empleo en la base de datos MEDLINE, mediante la utilización de los conectores booleanos, adaptándose posteriormente a las otras bases de datos anteriormente mencionadas (Tabla 1). La búsqueda se realizó de los últimos 6 años, hasta enero de 2013.

Tabla 1. Bases de Datos/ Descriptores

\begin{tabular}{|c|c|}
\hline BASES DE DATOS/FUENTES & DESCRIPTORES \\
\hline pubmed & $\begin{array}{l}\text { "Food-Processing Industry» AND «Hypersensitivity, Immediate» } \\
\text { "food industry" AND «hypersensitivity" }\end{array}$ \\
\hline scielo & $\begin{array}{l}\text { "food industry» AND «urticaria» } \\
\text { "food industry» AND «rhinitis» } \\
\text { «industry» AND «urticaria» }\end{array}$ \\
\hline embase & $\begin{array}{c}\text { "food industry" AND «alveolitis, extrinsic allergic" } \\
\text { Allergic AND Dermatitis }\end{array}$ \\
\hline scopus & $\begin{array}{l}\text { "food industry» AND «asthma" } \\
\text { "fishing» AND «hypersensitivity» }\end{array}$ \\
\hline lilacs & $\begin{array}{l}\text { "meat packing industry» AND «hypersensitivity» } \\
\text { Asma AND Ocupacional }\end{array}$ \\
\hline Osh update & $\begin{array}{c}\text { Industria AND alimentos } \\
\text { Hipersensibilidad AND profesional }\end{array}$ \\
\hline www.ilo.org cisdoc database & $\begin{array}{l}\text { Sensibilización AND Industria AND Alimentaria } \\
\text { "food industry» AND «eczema" } \\
\text { Food AND Sensitization }\end{array}$ \\
\hline
\end{tabular}




\begin{tabular}{cc}
\hline BASES DE DATOS/FUENTES & DESCRIPTORES \\
\hline www.ibecs.isciii.es & $\begin{array}{c}\text { "meat industry» AND «hypersensitivity» } \\
\text { "brewery» AND «hypersensitivity» }\end{array}$ \\
\hline www.sciencedirect.com & "cannery» AND «allergy" \\
"meat industry» AND «allergy» \\
"food processing industry» AND «allergy"
\end{tabular}

La selección de los artículos y la elección final de los trabajos se realizó de acuerdo a los siguientes criterios de inclusión: Población trabajadora de la industria alimentaria con clínica de hipersensibilidad respiratoria y/o cutánea de ambos sexos y trabajos originales.

Se excluyeron aquellos artículos referidos a estudios relacionados con alergias alimentarias, caracterización de antígenos y patología por productos irritantes. Artículos no originales, serie de casos y estudios transversales con una muestra inferior a 30 individuos. Se rechazaron aquellos artículos duplicados.

Los artículos seleccionados se distribuyeron de forma aleatoria y al azar, entre las participantes de la revisión bibliográfica; posterior al análisis de cada artículo, se discutía en consenso la asignación del nivel de evidencia correspondiente a través de los criterios SING ${ }^{9}$.

\section{RESULTADOS}

Se localizaron un total de 7.796 trabajos cuya distribución según fuente de información se detalla en la tabla 2. De estos trabajos, tras aplicar los criterios de inclusión y exclusión se seleccionaron 55, de los cuales 29 fueron eliminados por tratarse artículos duplicados. Tras someterlos a una evaluación de pertinencia, fueron eliminados 32. Quedando finalmente seleccionados 23 artículos para su revisión sistemática.

De los 23 estudios que entraron en la revisión el diseño más frecuente fue el de cohorte (9), seguido de los estudios trasversales (8), serie de casos (5) y un ensayo clínico.

C. Cambell y cols..$^{10}$ estudiaron en un estudio transversal, en 2007, una muestra de 53 trabajadores de una compañía de procesamiento de alimentos expuestos al lupino. Sus resultados evidencian que el $21 \%$ del total de trabajadores estudiados dieron prick test positivo para lupino. El grupo sensible al lupino tuvo una tendencia a la atopía $(\mathrm{p}=0,06)$ y el 64\% de ellos tuvo sintomatología de rinitis y sibilancias. (Cuadro 1).

E Mounier-Geyssant y cols. ${ }^{11}$ estudiaron en el año 2007 la variación estacional de la prevalencia de exposición a harina en una muestra de 286 aprendices de panadería y pastelería, sus resultados evidencian que los valores de exposición son mayores en durante las épocas frías $\mathrm{p}=0,009$.

En el 2007, T. Skjold y S.C.Nielsen ${ }^{12}$ estudiaron, mediante un diseño de cohorte la incidencia de atopía y síntomas respiratorios en una muestra de 178 aprendices de panaderos al inicio de su formación. La incidencia de atopía, síntomas pulmonares y síntomas nasales fue del 32\%, 19,8\% y 25,5\% respectivamente. Hubo 7 casos de asma $(3,7 \%)$ y 21 de síntomas asmatiformes $(11,2 \%)$.

En 2007, Yen Loo Lim y Goon Anthony ${ }^{13}$ estudiaron a 125 pacientes con enfermedades profesionales cutáneas, mediante un diseño de cohorte retrospectivo. Los resultados evidencian una incidencia de dermatisis de contacto irritativa del $62,4 \%$ y alérgica del 37,6\%. La incidencia de dermatitis de contacto ocupacional fue de $62,5 \%$ casos / año. 
JH. Jacobs y cols. ${ }^{14}$ estudiaron en 2008 en una muestra de 860 panaderos expuestos a trigo, la prevalencia de sensibilización y alergia relacionada con la exposición profesional. Sus resultados evidencian que las tasas de prevalencia y la frecuencia de sintomatología respiratoria y asma ocupacional aumenta con los niveles medios de exposición al trigo hasta, aproximadamente, unos valores de $25-30 \mathrm{microgr} / \mathrm{m}^{3}$.

M.Katz y cols. ${ }^{15}$ estudiaron en 2008 una muestra de 225 trabajadores de hostelería y panadería con dermatitis ocupacional localizada en mano, la eficacia de diferentes estrategias de reclutamiento para un programa de prevención. Sus resultados evidencian que el compromiso de los trabajadores para unirse al programa de prevención aumentó del $30 \%$ al $54 \%$ en el grupo de trabajadores que recibió una carta de invitación personalizada.

V. Van Kampen y cols. ${ }^{16}$ estudiaron en el año 2008, en un estudio de prevalencia una muestra de 107 panaderos que habían solicitado una indemnización por asma ocupacional. Se obtuvo una prevalencia de prueba de provocación positiva de un $67 \%$ en aquellos panaderos que presentaban síntomas respiratorios, de los cuales un $52 \%$ fueron positivos a harina de trigo y un $66 \%$ a harina de centeno. Sus resultados ponen en evidencian que las pruebas de provocación con harinas deben ser consideradas de preferencia.

T. Skjold y R Dahl ${ }^{17}$ estudian, en el 2008, una cohorte de 114 aprendices de panadería. La incidencia acumulada de rinitis fue de 41,2\%, síntomas asmatiformes (20,5\%), prick test positivo $(31,1 \%)$ y sensibilización ocupacional $(6,1 \%)$. La densidad de incidencia de rinitis fue 22 casos/100 personas-año, de síntomas asmatiformes 10 casos/100 personasaño y de asma ocupacional solo hubo un caso.

T. Malkonen y cols. ${ }^{18}$ estudiaron, en 2009, en una muestra de 1.048 trabajadores diagnosticados con dermatosis laboral los factores pronósticos de riesgo para la continuidad de la dermatosis laboral mediante un diseño de serie de casos. Sus resultados evidenciaron que la dermatosis laboral se mejoraba en un $17 \%$ de los que no cambiaron de puesto y $34 \%$ de los que cambiaron de puesto de trabajo. La mejor compensación se produjo en los pacientes con urticaria de contacto (35\%) mientras que la curación de las alérgicas fue de $27 \%$ y las irritantes de $23 \%$.

R. Baatjies y cols. ${ }^{19}$ estudiaron, en 2009, en una muestra de 517 panaderos, los factores fenotípicos determinantes de la respuesta asmática utilizando un diseño transversal. Sus resultados evidencian que la prevalencia de los fenotipos relacionados con el asma ocupacional (OA, 13\%) fue superior a la prevalencia de atopía (6\%) y de asma agravada por el trabajo (3\%).

A. Heutelbeck y cols. ${ }^{20}$ estudiaron, en 2009, en una muestra de 42 ganaderos, la exposición a los alérgenos de diferentes razas de ganado y su importancia en las alergias laborales mediante un diseño de corte. Sus resultados evidencian que el $32 \%$ de los ganaderos sintomáticos mostraron resultados negativos en los tests realizados con antígenos comerciales, sin embargo dieron resultados positivos para el inmunoblotting con alérgenos del pelo de ganado.

Sylvia Teo y cols. ${ }^{21}$ estudiaron, en 2009, en una muestra de 335 profesionales de restaurantes, catering y establecimientos de comida rápida: el tipo, la prevalencia y los factores de riesgo para las dermatosis profesionales utilizando un diseño transversal. Los resultados evidencian que el 19\% presentaron dermatosis ocupacional (DO) o quemaduras; el $10 \%$ dermatitis de contacto ocupacional con una prevalencia período de 12 meses (siendo todas dermatitis de contacto irritativa) y el $8 \%$ con una prevalencia período de 3 meses. La prevalencia período de 3 meses para las quemaduras fue del $6 \%$, no hubo ningún caso de dermatitis de contacto alérgica y diez trabajadores tenían otras dermatosis profesionales entre ellas urticaria alérgica de contacto para camarón y langosta.

K. Cummings y cols. ${ }^{22}$ estudiaron en 2010 en una muestra de 213 empleados de una planta de procesamiento de soja las consecuencias respiratorias adversas asociadas con la exposición ocupacional. Sus resultados evidencian que los trabajadores con IgE específica para la soja tienen 3 veces más probabilidad de presentar asma o síntomas 
asmatiformes y se asoció con el trabajo de producción y con las concentraciones pico de polvo.

E. Page y cols. ${ }^{23}$ estudiaron, en 2010, en una muestra de 186 panaderos, la exposición al polvo de harina y sensibilización laboral mediante un diseño trasversal. Sus resultados evidencian que los trabajadores del grupo con mayor exposición, tuvieron mayor prevalencia de sibilancias, rinitis, congestiona nasal y estornudos en comparación con el grupo de menor exposición. La prevalencia de IgE específica al trigo fue más alta en el grupo de mayor exposición.

M. F. Jeebhay y cols. ${ }^{24}$ estudiaron en el año 2010 en una muestra de 594 empleados de dos plantas de procesamiento de pescado en Sudáfrica, la prevalencia de sensibilización y los síntomas relacionados con el trabajo mediante un diseño transversal. Sus resultados evidencian que los síntomas oculo-nasales (26\%) fueron más frecuentes que los síntomas del asma (16\%). La prevalencia de atopía fue de 36\%, un $7 \%$ presentaban una sensibilización a diferentes especies de pescado y un $26 \%$ tenían más probabilidades de presentar síntomas de asma relacionados con el trabajo.

E. Meijer y cols.$^{25}$, en 2010 , estudiaron una muestra de 73 trabajadores expuestos al polvo de harina y estiman la probabilidad individual de estar sensibilizado a trigo y/o $\alpha$-amilasa mediante la clasificación de los trabajadores en tres grupos de riesgo (bajo, intermedio y alto) aplicando un modelo predictivo basado en un cuestionario y usando un diseño de cohorte prospectivo. Se observó una sensibilización a trigo del 39,7\%, $\alpha$-amilasa $9,6 \%$ y centeno $51,1 \%$; en cuanto a sintomatología la rinitis asociada al trabajo apareció en un $58,8 \%$, el asma laboral en un $13,7 \%$ y el asma exacerbada en el trabajo en el 4,1\%. En el grupo con alta exposición la tasa de sensibilización predictiva a trigo y/o $\alpha$-amilasa en comparación con la observada fue del $42,7 \%$ vs $41,5 \%$; la sensibilización a trigo en éste grupo fue 6 veces mayor que en el de baja exposición $(34,1 \%)$ y la sensibilización a $\alpha$-amilasa 2 veces superior (16,3\%). El $70 \%$ de ataques de asma (12 últimos meses) se encontraban en éste último grupo, al igual que el $69 \%$ de las conjuntivitis, el $61 \%$ de las rinitis y el $60 \%$ de los pacientes que usaron inhaladores. 7 de 8 tuvieron que cambiar de trabajo o de tarea realizada.

D. Gautrin y cols. ${ }^{26}$ estudiaron, en 2010, una cohorte de 215 trabajadores de plantas de procesamiento del cangrejo de las nieves mediante un diseño prospectivo, con el fin de estimar la prevalencia de asma ocupacional y asma alérgico ocupacional y determinar la relación entre la exposición al cangrejo y el asma ( $\mathrm{AO}$ y AOA) y a otros factores de riesgo como el tabaco. Los resultado mostraron una prevalencia de asma ocupacional (AO) del 15,8\% y una prevalencia de asma ocupacional alérgico (AAO) del 14,9\%.

Horst Christoph Broding y cols. ${ }^{27}$ estudiaron en 2011, en una muestra de 178 granjeros y panaderos el estado de la salud respiratoria mediante un diseño de cohorte retrospectivo. Los sujetos estudiados refirieron síntomas de vías respiratorias bajas (55,6\%), vías altas (66,3\%), tos y expectoración (50\%), visitas al médico (50\%), uso de alguna medicación (50\%). Los síntomas aparecieron de forma más frecuente en granjeros, con diferencias estadísticamente significativas: $\mathrm{p}<0.001$ de vías respiratorias bajas, $\mathrm{p}$ $<0.01$ vías respiratorias altas, $\mathrm{p}<0.0001$ tos, medicación y puntuación máxima, $\mathrm{p}<0.01$ visitas médicas. La puntuación total media fue 3,92 $\pm 2,90$ (media 4) puntos, y el 43,3\% de los pacientes tuvieron más de 4 puntos (granjeros una probabilidad 4 veces superior que los panaderos de presentar una puntuación máxima mayor de 4 puntos, 4,03 (2,137,66).

Lotte Vester y cols. ${ }^{28}$ estudiaron, en 2012, en una muestra de 336 trabajadores de la industria alimentaria (chef, panaderos, trabajadores en cocina) la frecuencia de dermatosis ocupacionales de las manos mediante un diseño de cohorte retrospectivo. Los resultados evidencian una incidencia del $57 \%$ de dermatitis de contacto irritativa (DCI), $22 \%$ de dermatitis de contacto proteínica (DCP), 1,8\% alérgica (DCA) y 2,4\% de urticaria de contacto (UC). 
Walter Mazzucco y cols. ${ }^{29}$ estudiaron, en el año 2012, en una muestra de 94 trabajadores del sector pesquero mediante un diseño transversal, la prevalencia de sensibilización a Anisakis simplex (AS) en el entorno laboral, y la posible asociación entre el contacto con el parásito y la actividad profesional. Sus resultados evidencian que un $36,1 \%$ de los trabajadores presentaron síntomas potencialmente indicativos de antecedentes alérgicos ( $\mathrm{p}=0,08)$, el $17,7 \%$ de ellos tenían niveles elevados de IgE específica para el AS, prevalencia que no resultó ser estadísticamente significativa $(p=0,15)$, en comparación con el $8,3 \%$ de los que no refieren síntomas alérgicos. Se encontraron niveles elevados de IgE total en el $19,8 \%$ de los trabajadores y para IgE específica a AS el resultado fue de una prevalencia del $11,7 \%$. 


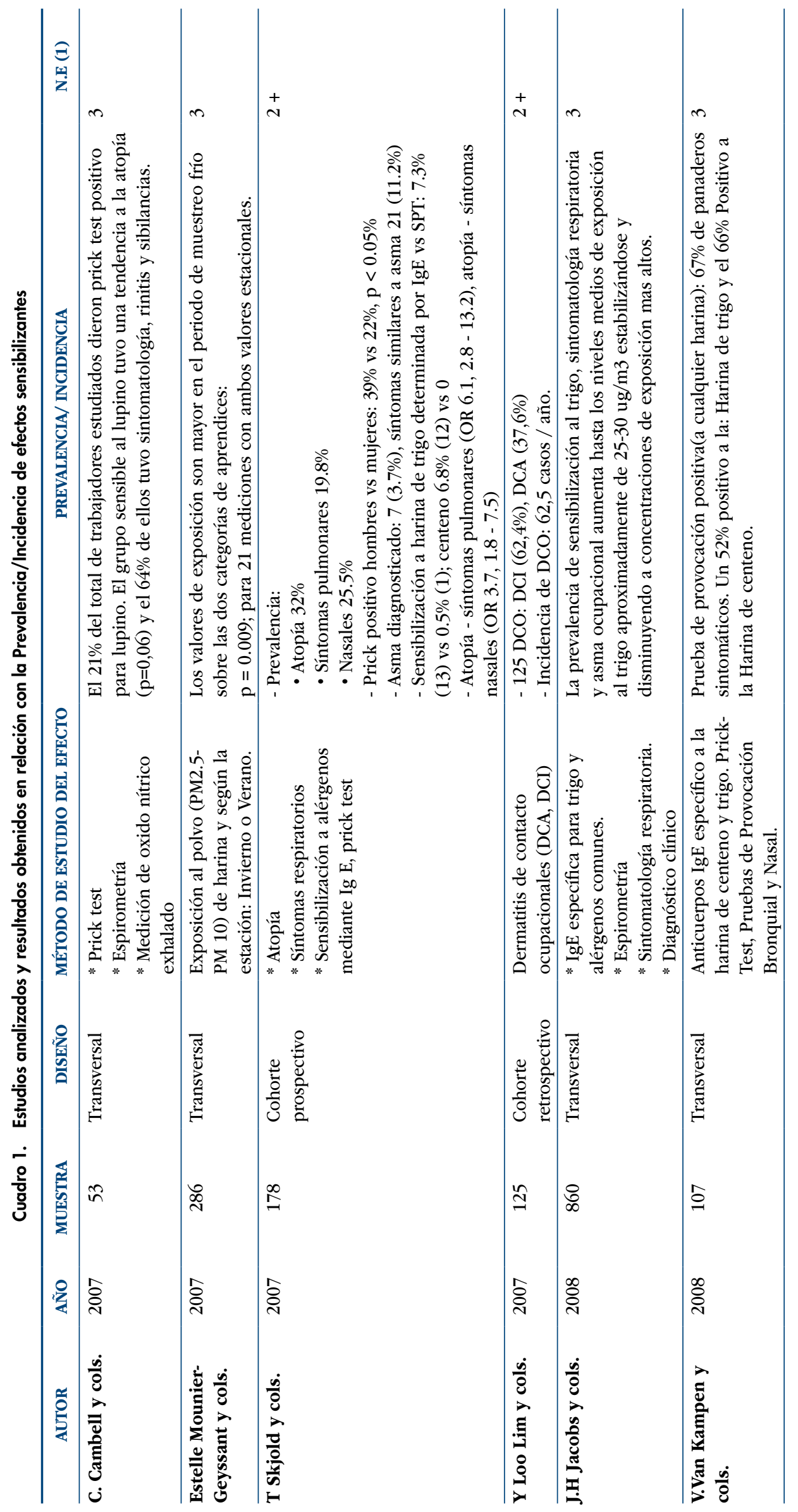




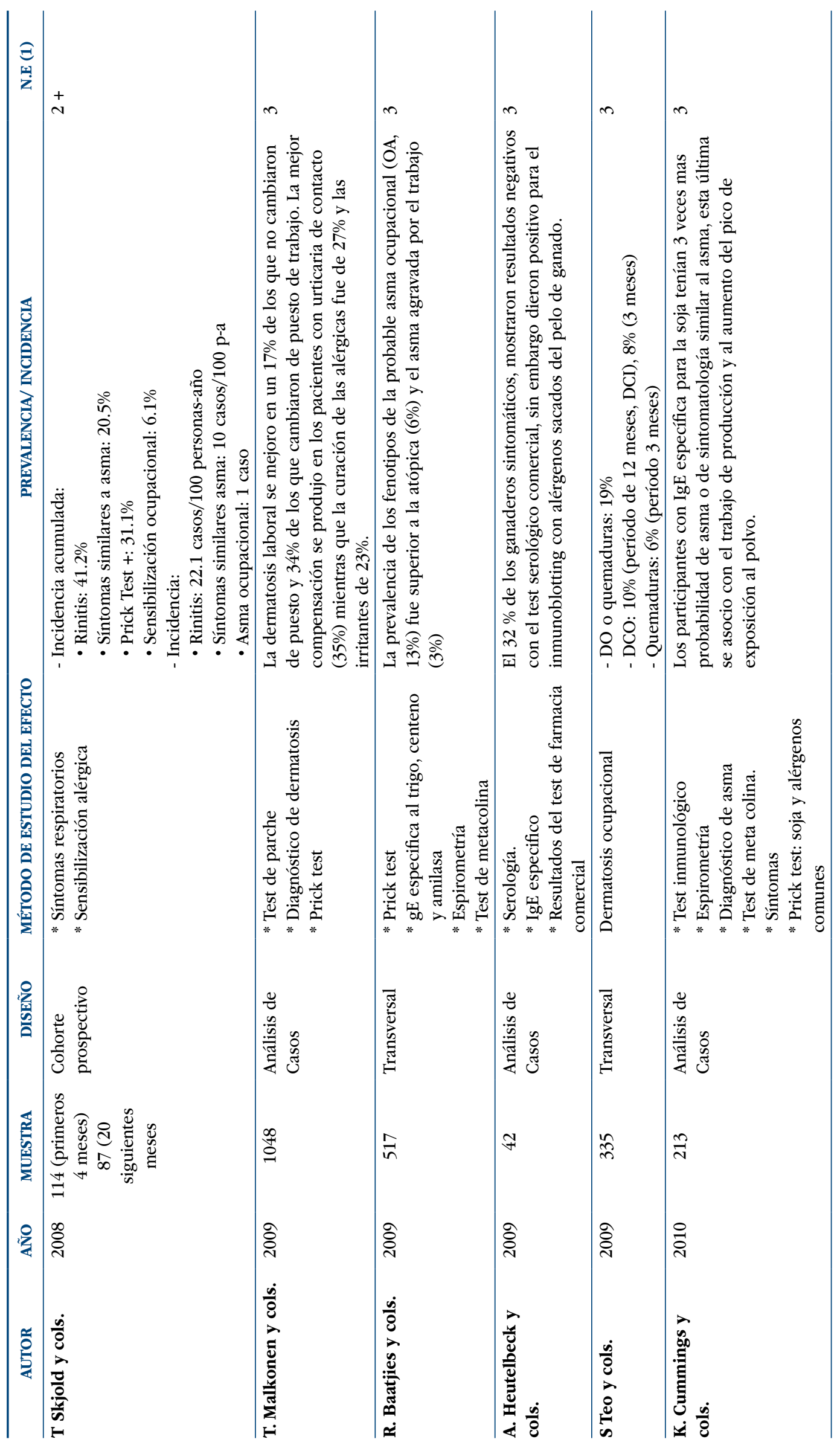




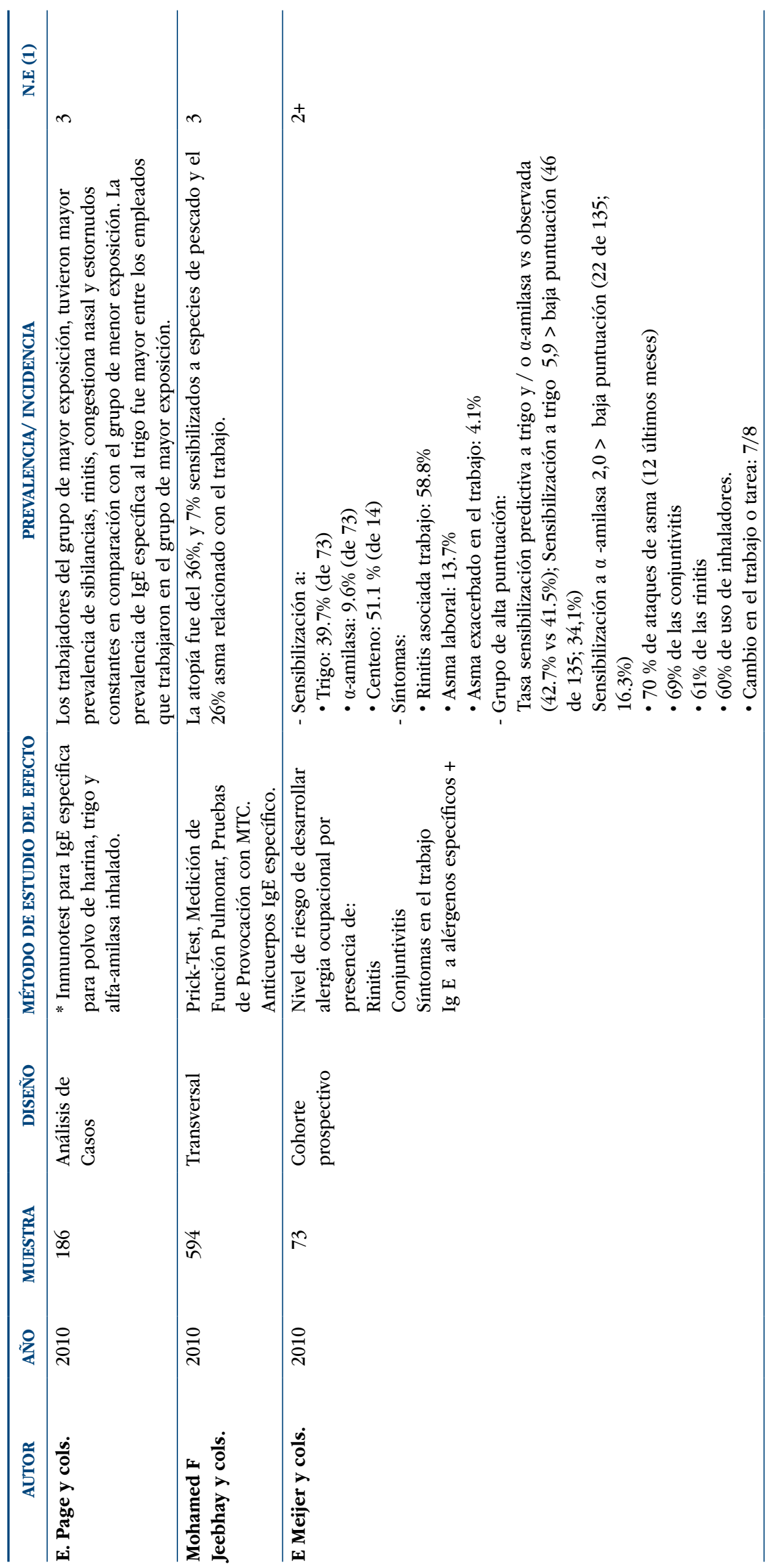




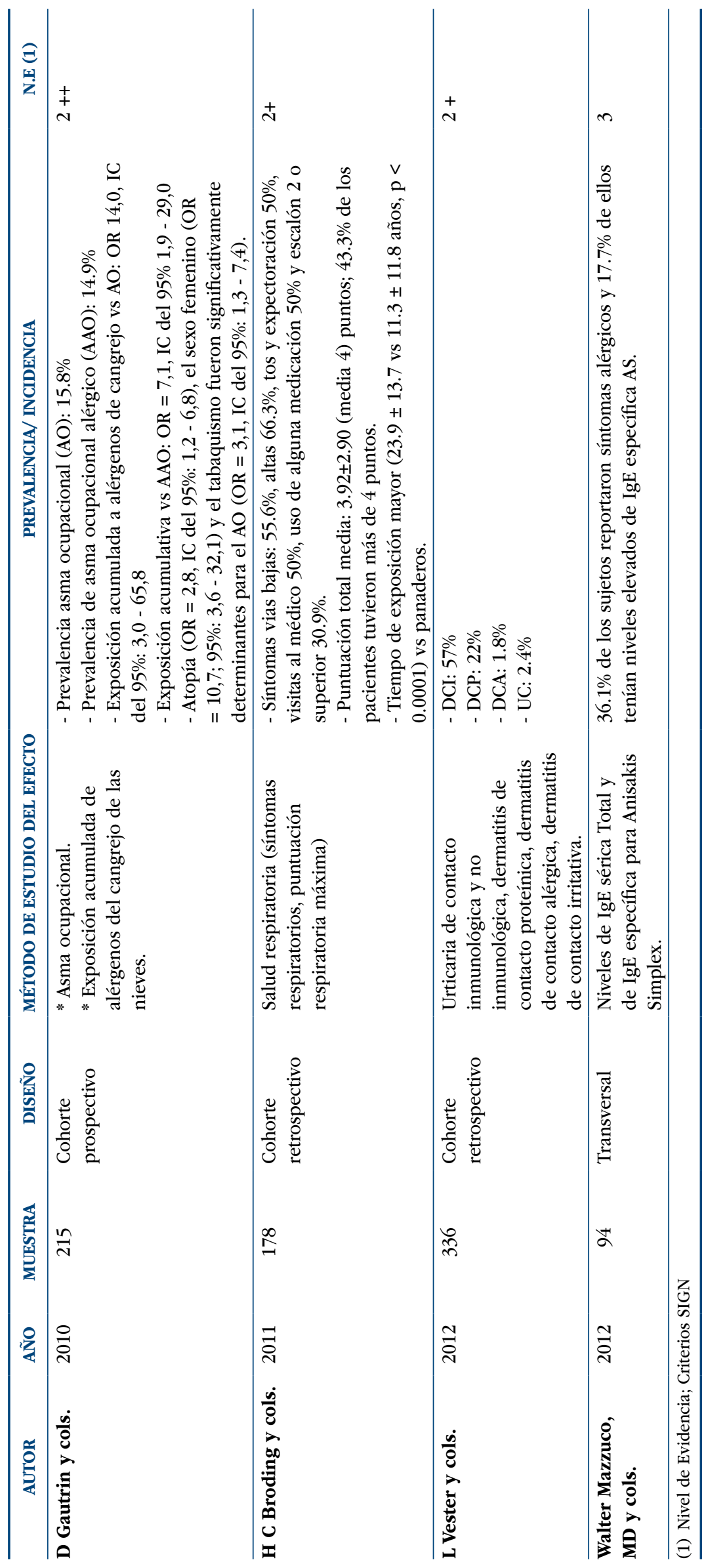


En el estudio de JH. Jacobs y cols. ${ }^{14}$ se evidenció que los panaderos con una exposición acumulada a alérgeno del trigo tuvieron una probabilidad 2 veces mayor de presentar sintomatología de vías respiratorias bajas $(\mathrm{OR}=2)$ y una probabilidad 4 veces mayor de padecer asma alérgico relacionada con el trabajo $(\mathrm{OR}=3,5 ; \mathrm{OR}=4,5$ para la exposición media y acumulativa respectivamente) (Cuadro 2).

En el estudio de K.Cummings y cols. ${ }^{22}$ los empleados de una planta de procesamiento de soja con IgE específica para la soja tenían 3 veces más probabilidad de asma o de sintomatología asmatiforme (sibilancias $\mathrm{OR}=2,1 ; \mathrm{IC}=1,5-2,8$; sinusitis $\mathrm{OR}=2,0 ; \mathrm{IC}=1,6-2,5$; síntomas similares al asma $\mathrm{OR}=1,8 ; \mathrm{IC}=1,2-2,8$; asma $\mathrm{OR}=1,7 ; \mathrm{IC}=1,0-2,9$ ).

Los resultados del estudio de $\mathrm{H}$. Christoph Broding y cols. ${ }^{27}$ evidenciaron un tiempo mayor de exposición a alérgenos en granjeros con respecto a panaderos $(23,9 \pm 13,7$ vs 11,3 $\pm 11,8$ años, $\mathrm{p}<0,0001$ ); la proporción de granjeros que habían estado trabajando más de 10 años fue de un 77,5\%, comparada con el 36,6\% de los panaderos ( $<<0,0001)$. Los granjeros tenían 3 veces más probabilidad de desarrollar tos $(\mathrm{OR}=3,63$; $\mathrm{IC}=1,21-5$, y 3 más de uso de medicación ( $\mathrm{OR}=3,59 ; \mathrm{IC}=1,62-7,97)$.

El estudio de Mohamed F. Jeebhay y cols. ${ }^{24}$, evidencian en sus resultados que los empleados de procesamiento de pescado y harina de pescado tenían una probabilidad 2 veces mayor de sensibilización a la proteína del pescado y al polvo de harina.

J. Harris-Roberts y cols. ${ }^{30}$ estudiaron, en el año 2009, una muestra de 225 trabajadores de pequeñas y medianas panaderías Británicas, mediante un diseño transversal, dónde evidenciaron que los panaderos asociaban opresión torácica en su lugar de trabajo con la sensibilización a la harina de trigo y de cualquier enzima añadida. 


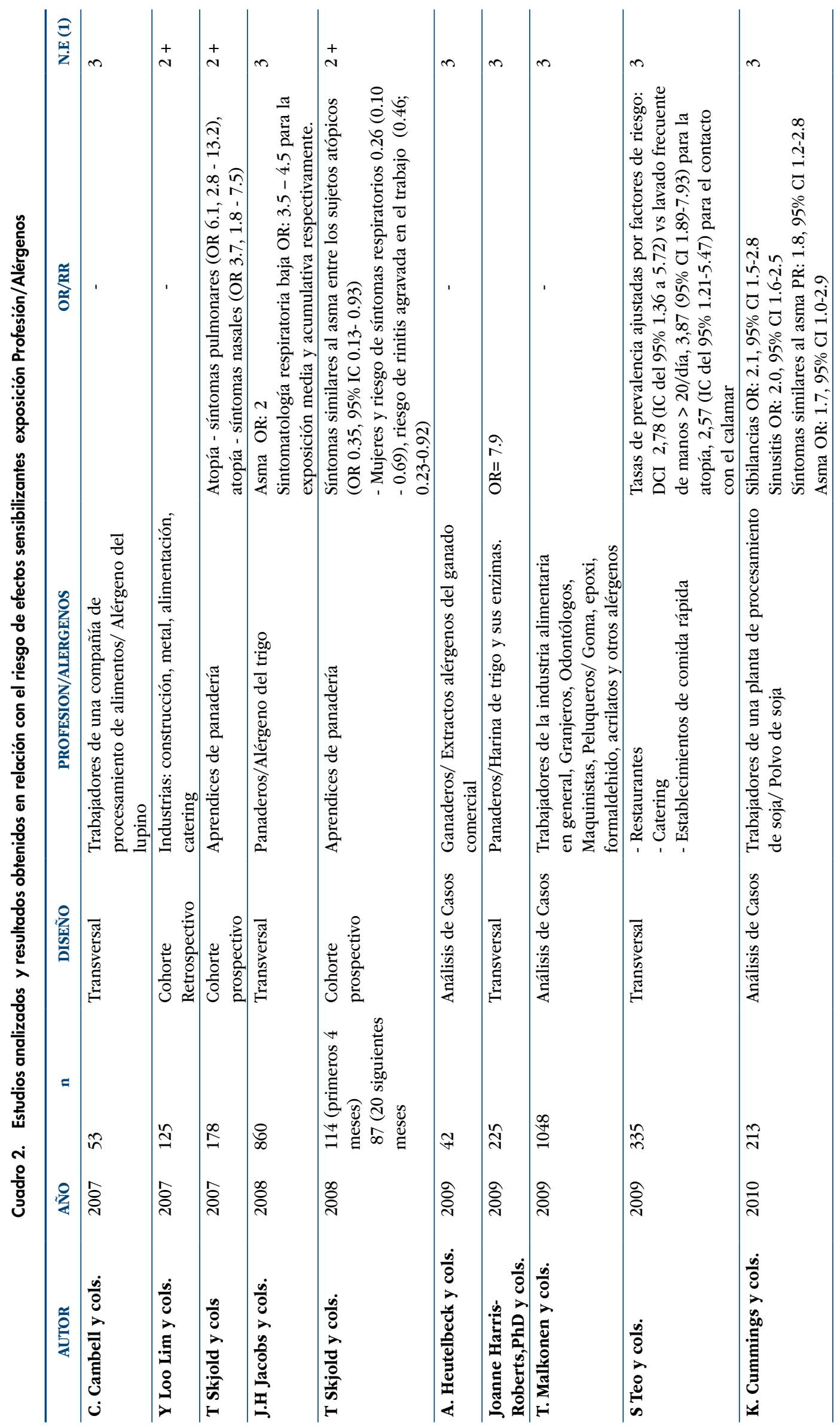




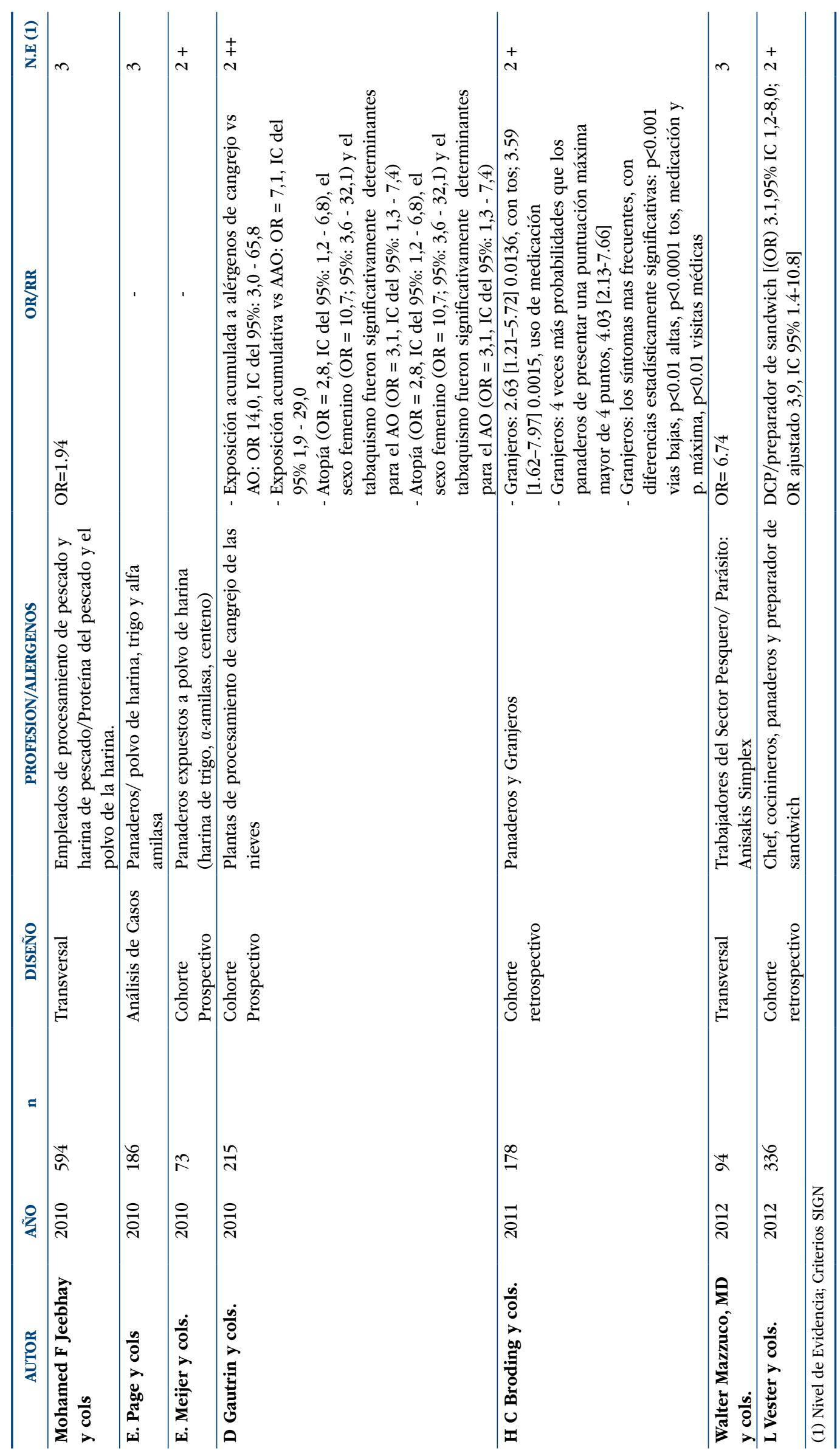


En el estudio de L. Lim se utilizaron las pruebas del parche para el diagnóstico de dermatosis de contacto. En el estudio de T. Skjold y R. Dahl prick test (SPT), ldeterminación de IgE, test de provocación con metacolina y espirometría las pruebas utilizadas, asociando el resultado de éstas con los distintos diagnósticos. El número de aprendices de panadería con una IgE total elevada ( $>0.150 \mathrm{kU}-\mathrm{l})$ fue mucho menor que el número con SPT positivas, 16 frente a 40 y 10 frente a 33 en el inicio y el final del seguimiento, respectivamente. El prick test con alérgenos de panadería fue positivo en un 4,38\%. $\mathrm{Al}$ igual que L.Vester, S.Teo también emplea la determinación del prick test y patch test, asociando la posibilidad de presentar sintomatología con la positividad a ellas. Gautrin y cols. emplearon la determinación de la IgE, prick test, test de provocación con metacolina y espirometría en los diagnósticos de asma. En el estudio de L.Vester y cols. emplearon la determinación del prick test y pruebas del parche y asocia la positividad a éstas con el diagnóstico de dermatitis de contacto ${ }^{[13,17,21,26,28 .}$ (Cuadro 3).

En el trabajo de T. Salol y S.C. Nielsen ${ }^{12}$ se utilizaron como pruebas diagnósticas el prick test, IgE, test de metacolina y espirometría. El SPT fue positivo en el 39\% de los hombres vs $22 \%$ de las mujeres, siendo ésta diferencia estadísticamente significativa ( $p$ $<0,05)$. La sensibilización a harina de trigo determinada por IgE en comparación con el SPT fue del 7,3\% vs $0,5 \%$; con centeno $6,8 \%$.

JH. Jacobs y cols. ${ }^{14}$ emplearon la determinación de IgE específica para trigo y alérgenos comunes, espirometría y sintomatología respiratoria para el estudio de la asociación entre exposición a trigo y enzimas y la aparición de presentar síntomas de rinitis alérgica, conjuntivitis alérgica.

K. Cummings y cols. ${ }^{22}$ emplearon para el estudio de asociación entre exposición a soja y respuesta alérgica test inmunológicos, espirometría, diagnostico de asma, test de metacolina y prick test para soja y alérgenos comunes.

En el estudio de T. Malkonen y cols. ${ }^{18}$ emplearon test de parche y prick test en el estudio de una serie de 1.048 trabajadores diagnosticados con dermatosis laboral en el instituto finlandés de salud ocupacional. La prevalencia de los cuadros diagnosticado fue: dermatitis de contacto alérgica (17\%), dermatitis de contacto irritativa (22\%), atopías (31\%), rinitis/conjuntivitis alérgica (14\%).

R. Baatjies y cols. ${ }^{19}$ emplearon la determinación de IgE específica al trigo, centeno y amilasa, prick test, espirometría y test de metacolina, para el estudio de cuadro de base inmunoalérgica en panaderos y la variabilidad de la repuesta en función del fenotipo.

E. Page y cols. ${ }^{23}$ emplearon la técnica del inmunotest para IgE específica de polvo de harina, trigo y $\alpha$-amilasa para el estudio de la asociación entre la presentación de síntomas de de dermatitis de contacto alérgica, atopías, rinitis alérgica, conjuntivitis alérgica, asma y la exposición a alérgenos habituales en la panificación.

El estudio de C.Cambell y cols. emplearon prick test, espirometría y medición de óxido nítrico exhalado para el estudio de la asociación entre atopía, presentar rinitis alérgica, eczema alérgico, rinoconjuntivitis y/o síntomas respiratorios de vías bajas, en un grupo de 53 trabajadores de la industria alimentaria y la sensibilización al lupino en el puesto de trabajo.

En el trabajo de A. Heutelbeck y cols. se emplearon pruebas inmunológicas, serología, IgE específica y resultados de un test comercial en el estudio de asociación entre dermatitis de contacto proteínica, rino-conjuntivitis alérgica, sintomatología asmatiforme y asma en un grupo de 42 granjeros expuestos a extractos comerciales de alergenos del ganado y su comparación con extractos autopreparados de diferentes razas de ganado $^{10,20}$. 


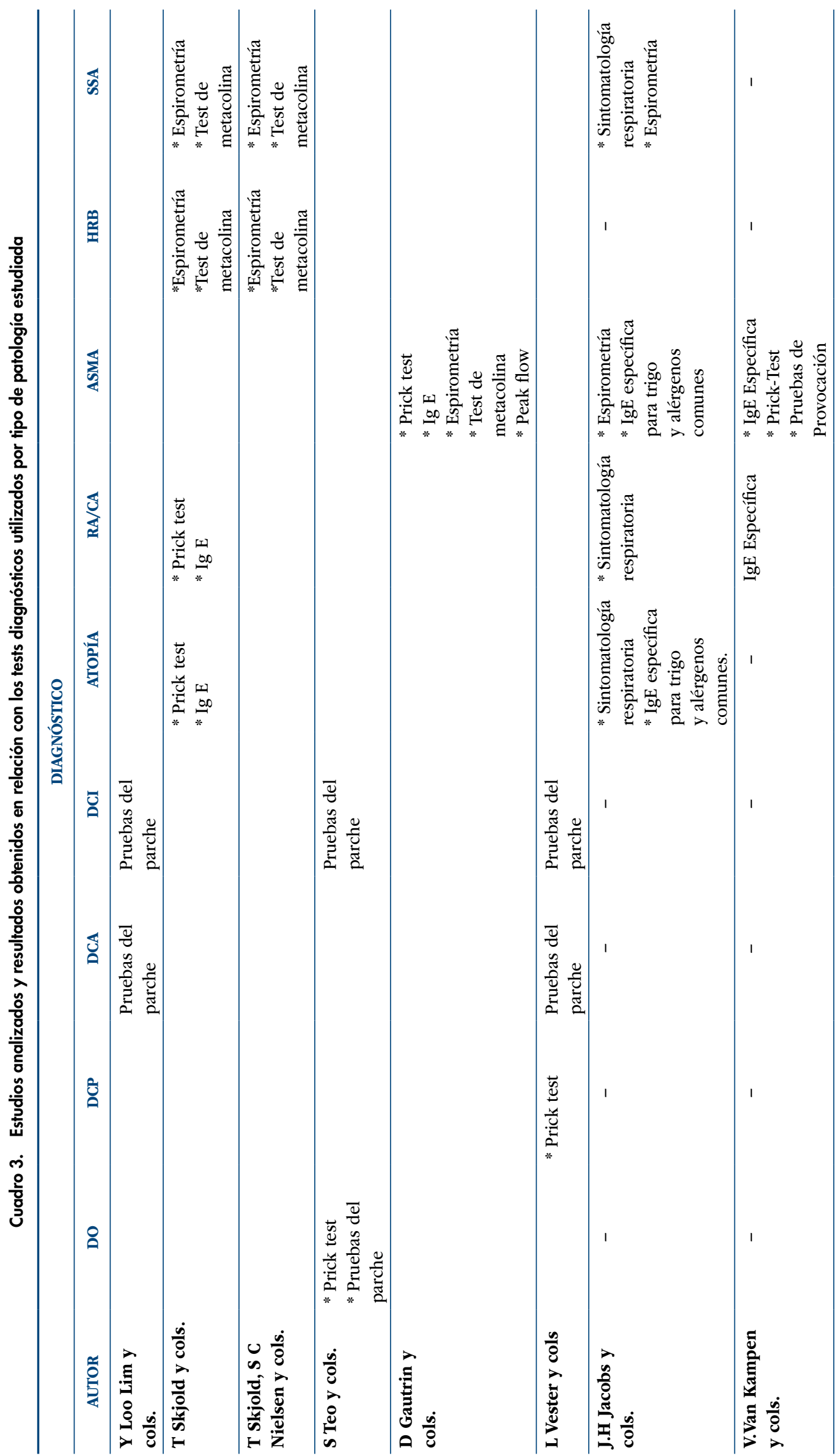




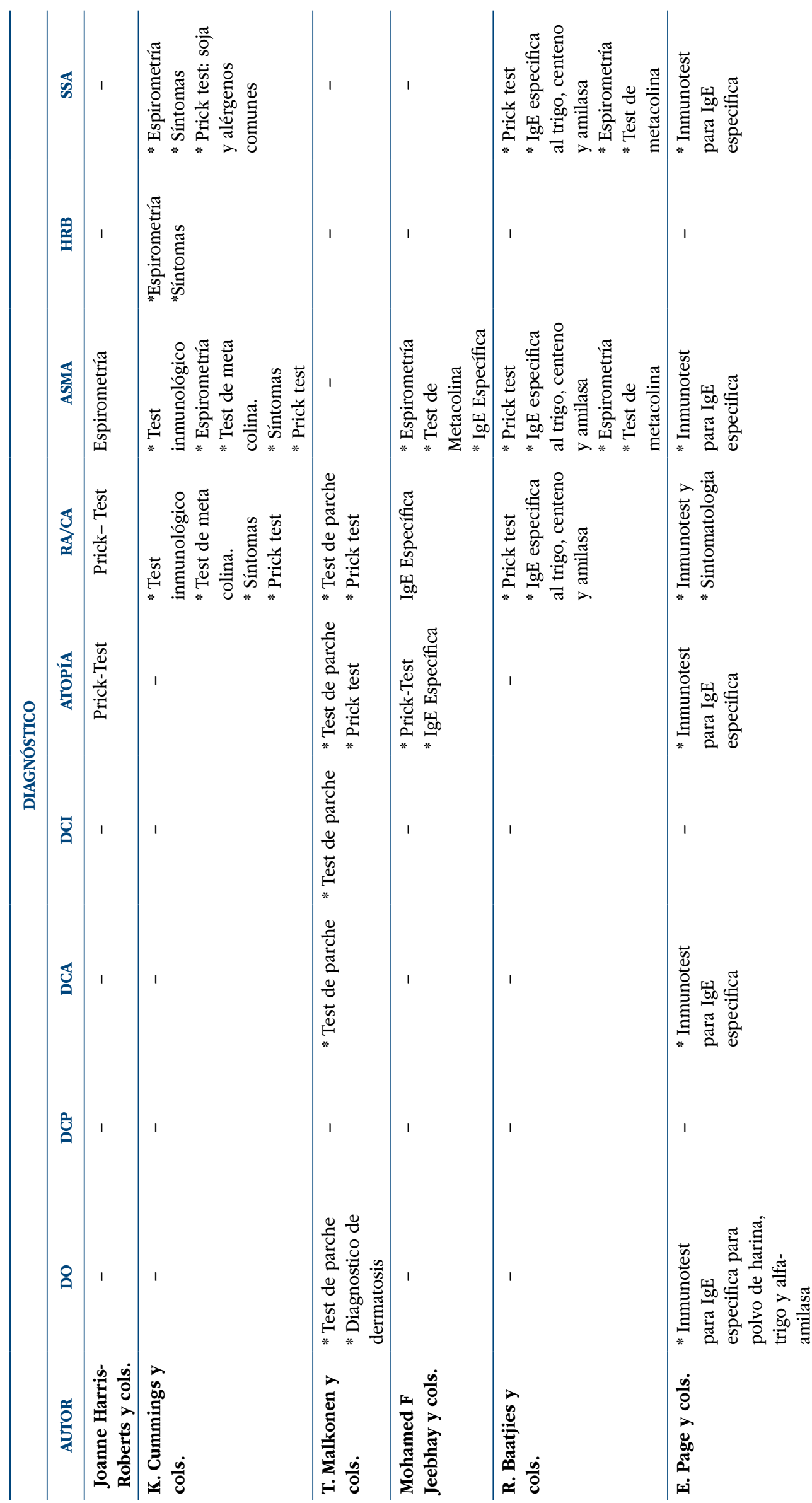




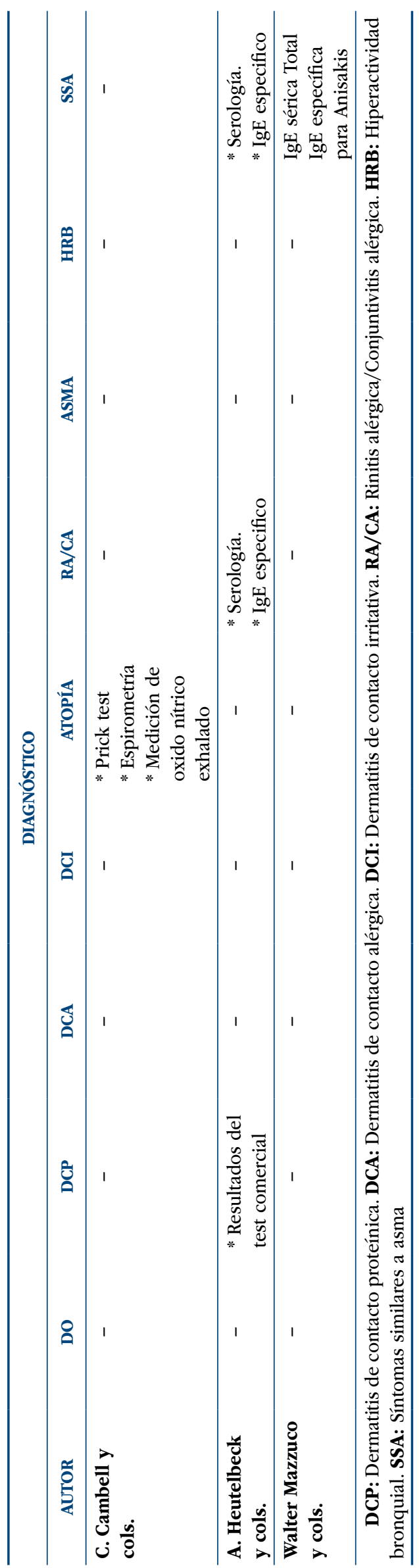


En el estudio de Joanne Harris-Roberts y cols. ${ }^{30}$ la atopía era el factor más predictivo en la determinación de la sensibilización, sus resultados evidenciaron una asociación 18 veces mayor de sensibilización en un grupo de panaderos con atopía; además evidenciaron que los panaderos fumadores tenían una probabilidad 5 veces superior de respuesta alérgica, considerándolo un importante factor de riesgo para la sensibilización a la harina de trigo o de enzimas en los trabajadores atópicos. (Cuadro 4).

T. Skjold y R. Dahl evidenciaron un aumento significativo del riesgo de síntomas asmatiformes entre sujetos atópicos ( $\mathrm{OR}=0,35 ; \mathrm{IC}=0,13-0,93)$; las mujeres tenían significativamente un mayor riesgo de síntomas respiratorios $(\mathrm{OR}=0,26 ; \mathrm{IC}=0,10-0,69)$.

El estudio de Horst Christoph Broding y cols. demostraron que en los panaderos la exposición a alérgenos laborales durante más de 10 años incrementa 6 veces el riesgo de obtener una peor puntuación en la valoración de su salud respiratoria $(\mathrm{OR}=6,48 ; \mathrm{IC}=2,04-20,56)$; sin embargo entre los granjeros la exposición a alergenos laborales no explica la gravedad de los síntomas respiratorios. Demostraron también que una exposición mayor a 10 años en panaderos está relacionada con una probabilidad 4 veces más alta de presentar clínica de vías respiratorias altas $(\mathrm{OR}=4,50 ; \mathrm{IC}=1,44-14,04)$, casi 5 veces más las visitas al médico $(\mathrm{OR}=4,60 ; \mathrm{IC}=1,53-13,80)$ y 4 veces más en el uso de medicación de $1 .^{\circ}-2^{\circ}$ escalón (OR=3,65; IC=1,25-10,66) vs $(\mathrm{OR}=4,21 ; \mathrm{IC}=1,21-14,69)$. En el subgrupo de granjeros, los pacientes de más de 40 años tuvieron una probabilidad 6 veces mayor de tener puntuación máxima por encima de 4 puntos $(\mathrm{OR}=6,06)$ casi 7 veces más de presentar síntomas vías respiratorias bajas ( $\mathrm{OR}=6,58 ; \mathrm{IC}=1,71-25.31) ; 5$ veces más visitas médicas $(\mathrm{OR}=5,42 ; \mathrm{IC}=1,43-20,54) ;$ y 6 veces más la toma de medicación perteneciente al $\geq 2 .^{\circ}$ escalón ( $\mathrm{OR}=6,17$; $\left.\mathrm{IC}=1,42-26,72\right)$. En los panaderos, en cambio, la edad mayor a 40 años estaba asociada a una probabilidad 4 veces mayor de presentar clínica de vías respiratorias bajas ( $\mathrm{OR}=3,98$; $\mathrm{IC}=1,46-10,82)$; 3 veces superior de tos y expectoración $(\mathrm{OR}=3,57 ; \mathrm{IC}=1,29-9,94)$; 4 veces másvisitas médicas $(\mathrm{OR}=4,24 ; \mathrm{IC}=1,51-11,95)$; y casi 4 veces mayor consumo de medicación del primer escalón $(\mathrm{OR}=3,62$; IC $=1$,339,80). Los panaderos que habían trabajado durante más de 10 años referían con más frecuencia clínica de vías respiratorias altas $(\mathrm{OR}=4,50 ; \mathrm{IC}=1,44-14,40)$, visitas al médico ( $\mathrm{OR}=4,60$; IC=1,53-13,80), escalón 1 ( $\mathrm{OR}=3,65 ; \mathrm{IC}=1,25-10,66)$ y 2 de tratamiento $(\mathrm{OR}=4,21 ; \mathrm{IC}=1,21-14,69)$. Además, los panaderos fumadores referían tos y expectoración con más frecuencia $(\mathrm{OR}=3,91 ; \mathrm{IC}=1,49-10,22)$ que los no fumadores, asociación ausente en granjeros.

Los resultados del estudio de L. Vester y cols. evidenciaron una probabilidad 3 veces mayor de presentar DCP en los preparadores de sándwiches $(\mathrm{OR}=3,1 ; \mathrm{IC}=1,2-8,0)$; (ORajustado=3,9; IC=1.4-10.8).

El trabajo de $\mathrm{S}$. Teo demuestra, mediante tasas de prevalencia ajustadas por factores de riesgo, que hay una probabilidad casi 3 veces mayor de desarrollar DCI en tareas dónde existe un lavado frecuente de manos de $>20 /$ día $(\mathrm{OR}=2,7$; $\mathrm{IC}=1,36-5,72)$; 4 veces más en atópicos $(\mathrm{OR}=3,87, \mathrm{IC}=1,89-7,93)$ y unas 2 veces más en aquellas en contacto con calamar $(\mathrm{OR}=2,57 ; \mathrm{IC}=1,21-5,47),{ }^{[17,27,28]}$.

En el estudio de T. Skjold y S.C. Nielsen los aprendices de panadero con atopía tuvieron una probabilidad 6 veces mayor de desarrollar síntomas pulmonares $(\mathrm{OR}=6,1$; $\mathrm{IC}=2,8-13,2)$ y una probabilidad 4 veces mayor de síntomas nasales (OR=3,7; IC=1,8-7,5). El trabajo de Gautrin y Cartier evidenció que una alta exposición acumulada a los alérgenos de cangrejo, se asoció con AO $(\mathrm{OR}=14,0 ; \mathrm{IC}=3,0$ - 65,8) y con AOA $(\mathrm{OR}=7,1$; $\mathrm{IC}=1,9$ - 29,0); la tarea desarrollada al comenzar los síntomas (limpieza, embalaje, congelación) fue un predictor de presentar AO (OR=3,9; IC=1,6-8,7) y AOA (OR=3,2; $\mathrm{IC}=1,4-7,5)$. En los sujetos con atopía se evidenció una probabilidad 3 veces mayor de presentar $\mathrm{AO}(\mathrm{OR}=2,8 ; \mathrm{IC}=1,2-6,8)$; en mujeres el riesgo de presentar AO fue de casi 11 $(\mathrm{OR}=10,7$; IC=3,6 - 32,1); el tabaquismo también fue significativamente determinantes para el $\mathrm{AO}(\mathrm{OR}=3,1 ; \mathrm{IC}=1,3-7,4)$.

Walter Mazzuco y cols. en sus resultados evidenciaron que dentro del sector pesquero los pescadores mostraron un aumento significativo, 6 veces superior, del riesgo de 
seroconversión a Anisakis simplex (AS), mientras que los pescaderos/empleados de limpieza de pescado experimentaron una probabilidad 5 veces mayor de seroconversión. En el estudio se utilizó la determinación de IgE sérica total e IgE específica a AS. Se observó una asociación entre presentar síntomas asmatiformes y la duración de la exposición ocupacional al parásito ${ }^{12,26,29}$.

V.Van Kampen y cols. en sus resultados evidenciaron que dependiendo de las concentraciones de IgE específica a harina, el valor predictivo positivo (VPP) oscilaba entre el $74 \%-100 \%$ para el trigo y el $82-100 \%$ para la harina de centeno, respectivamente. Los mínimos valores de corte con un VPP del 100\% fueron 2,32 KU/L (5,0 mm) para la harina de trigo y $9,64 \mathrm{KU} / \mathrm{L}(4,5 \mathrm{~mm})$ para la harina de centeno. Todos los panaderos con IgE específica a harina y prick-test positivo presentaron un test de provocación positivo. La especificidad fue del $68 \%$ y $62 \%$ para la harina de trigo, y centeno respectivamente y la sensibilidad del $87 \%$. Analizaron la probabilidad de que la IgE específica y prick test a harina de trigo y centeno fueran predictores de los resultados de pruebas de provocación específicas en panaderos con síntomas de asma, rinitis alérgica, conjuntivitis alérgica y atopía. Por otro lado, en el estudio realizado por Mohamed F. Jeebhay y cols. en sus resultados evidenciaron que los hombres que trabajaban en el procesado de pescado tenían 2,06 veces mayor probabilidad de sensibilizarse por contacto a especies de pescado y desarrollar AO. De igual forma Joanne Harris-Roberts y cols. asociaron la probabilidad de presentar síntomas de rinitis alérgica, conjuntivitis alérgica, atopía y asma relacionados con el lugar de trabajo, en panaderos sensibilizados a trigo y sus enzimas ${ }^{16,24,30}$. 


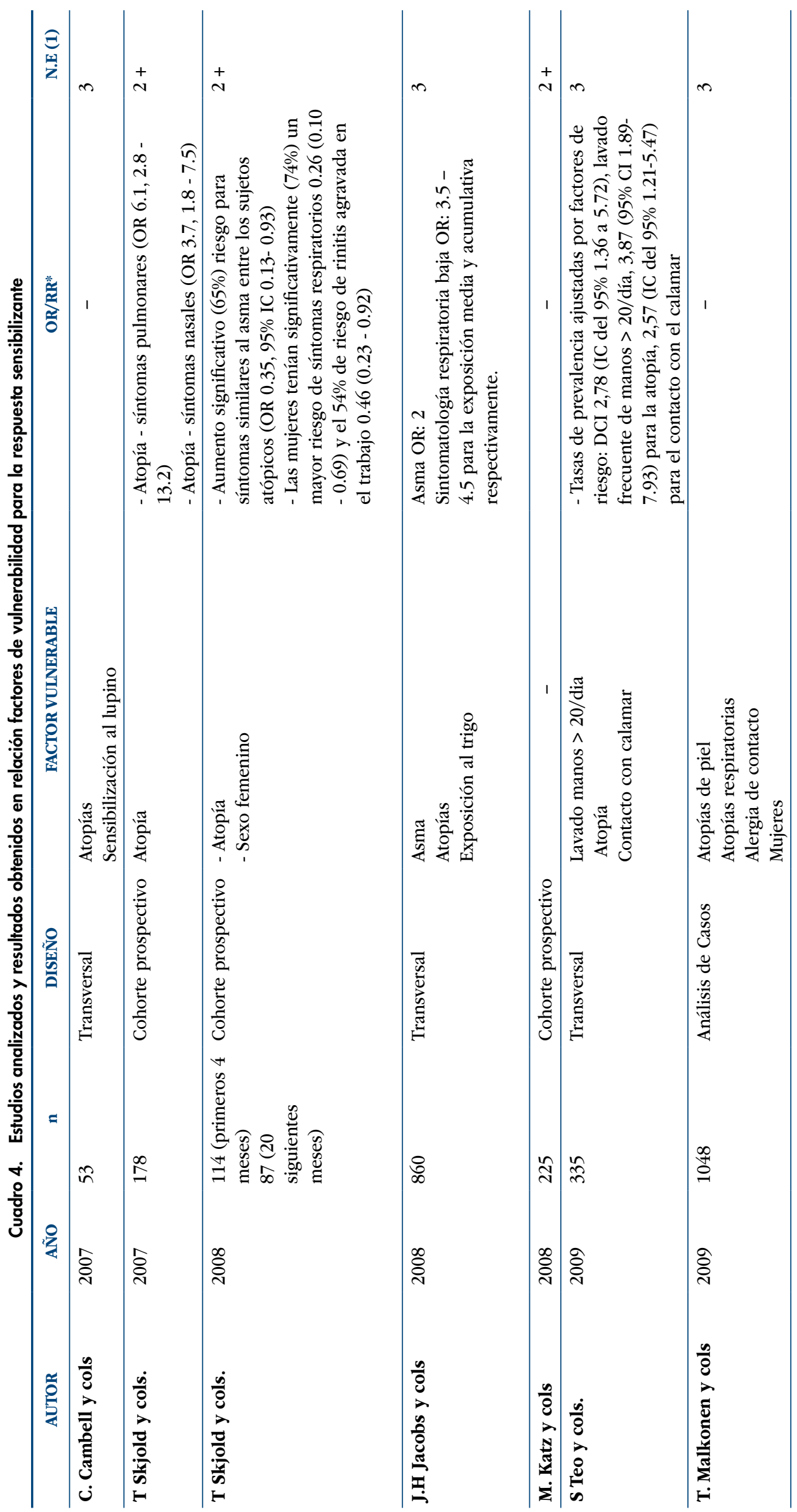




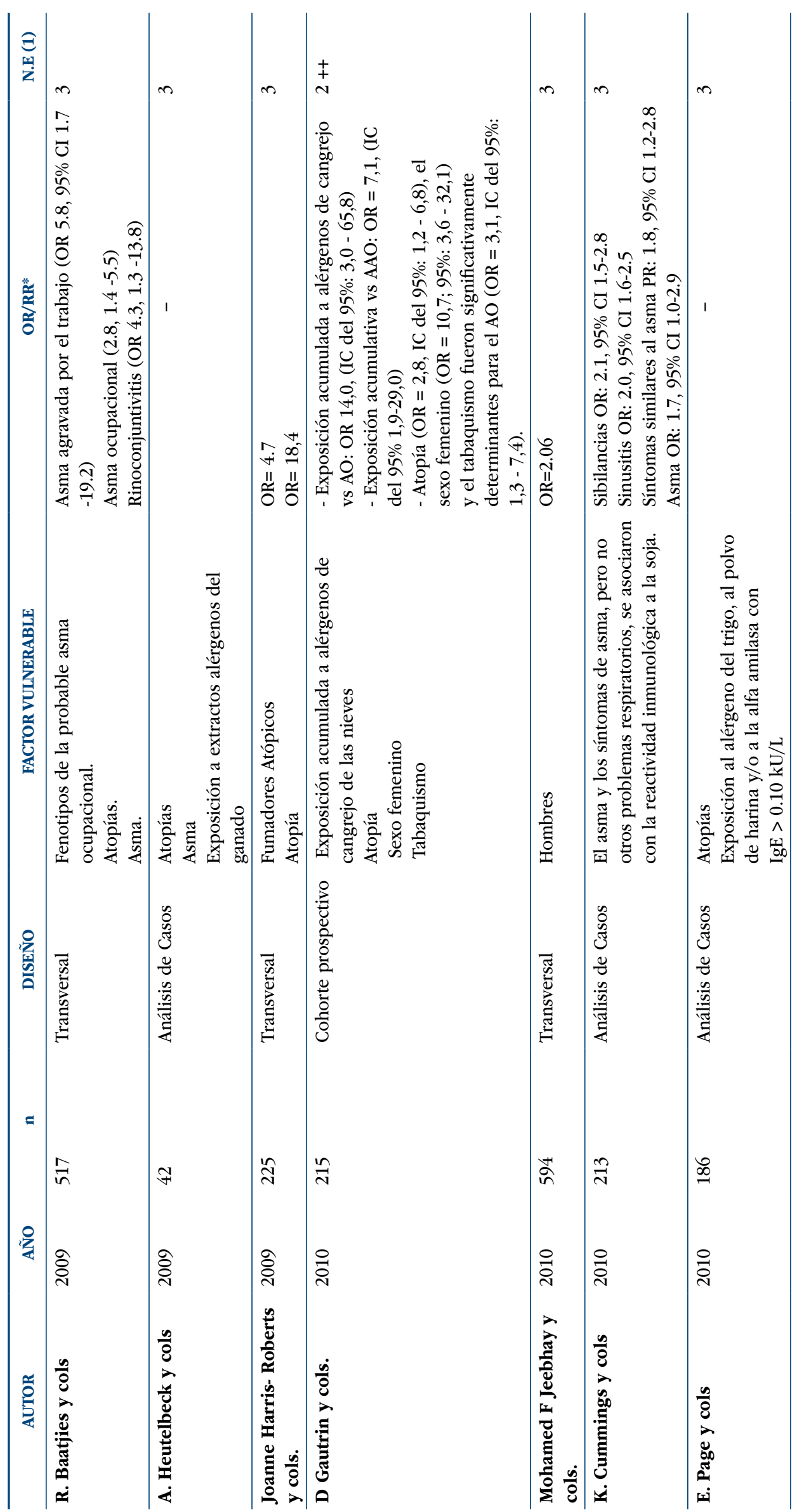




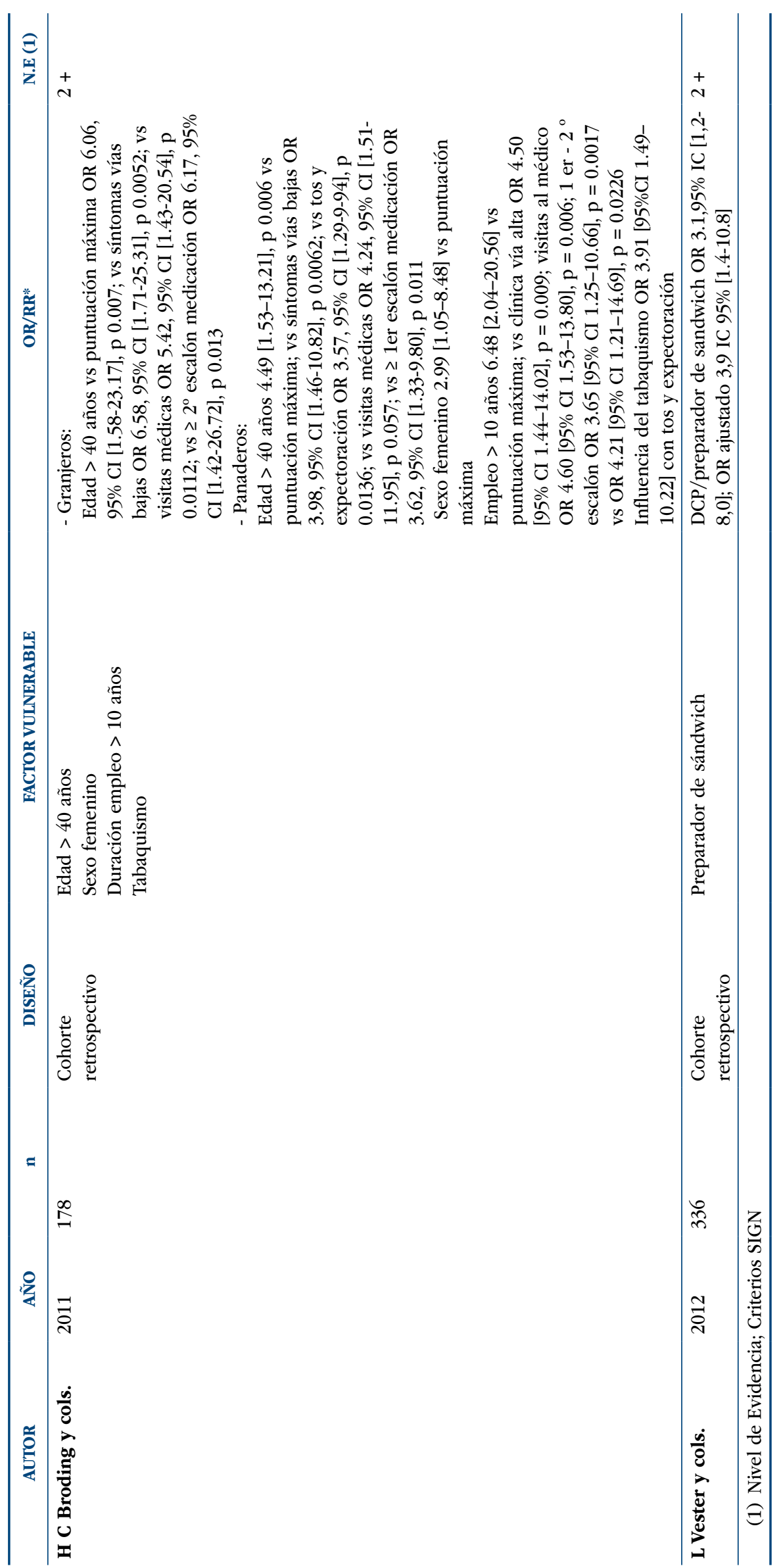




\section{DISCUSIÓN Y CONCLUSIONES}

Los trabajadores de la industria alimentaria, especialmente en el área de panadería, tienen una alta prevalencia de sensibilización al polvo de harina, trigo y $\alpha$-amilasa. En nuestra revisión, de los 23 artículos analizados, 8 de ellos estudiaron panaderos y la sintomatología respiratoria, asma ocupacional y sensibilización en general relacionada con la actividad laboral.

En cuanto a la sintomatología más frecuente entre los panaderos Horst Christoph Broding y cols. ${ }^{27}$ encontraron síntomas de vías respiratorias bajas en un 55,6\%, vías respiratorias altas (66,3\%), tos y expectoración (50\%). En contraste con el estudio anterior E. Meijer y cols. ${ }^{25}$ en 2010 observaron que la rinitis asociada al trabajo apareció en el $58,8 \%$, el asma laboral en un $13,7 \%$ y el asma exacerbado en el trabajo en el $4,1 \%$. Los artículos revisados relacionados con sensibilización en panaderos, concuerdan con estos autores en cuanto a la sintomatología más frecuente.

Los factores vulnerables como la exposición al alérgeno fueron valorados por Horst Christoph Broding y cols. ${ }^{27}$ quienes evidenciaron que los panaderos expuestos a alérgenos laborales durante más de 10 años tienen una probabilidad 6 veces mayor de obtener una peor puntuación en la valoración de su salud respiratoria. En concordancia con el estudio anterior, J.H. Jacobs y cols. ${ }^{14}$ evidenciaron que los panaderos con una exposición acumulada al alérgeno del trigo tuvieron una probabilidad 2 veces mayor de presentar sintomatología baja respiratoria y una probabilidad 4 veces mayor de padecer asma alérgico relacionada con el trabajo. E. Page y cols. ${ }^{23}$ evidencian que los panaderos más expuestos, tuvieron mayor prevalencia de sibilancias, rinitis, congestión nasal y estornudos constantes en comparación con el grupo de menor exposición.

En relación a la sensibilización a trigo y/o $\alpha$-amilasa E. Meijer y cols. ${ }^{25}$ en 2010 estimaron la probabilidad individual de sensibilización a estos alérgenos y observaron una sensibilización a trigo del $39,7 \%$, a $\alpha$-amilasa $9,6 \%$ y a centeno de $51,1 \%$.

Las atopías se relacionan con la sensibilización en los panaderos, Joanne HarrisRoberts y cols. ${ }^{30}$ determinaron que la prevalencia de atopía es el factor predictivo más importante en la determinación de la sensibilización, sus resultados evidencian una asociación 18 veces más importante para la sensibilización a alérgenos.

El habito tabáquico, fue valorado en el estudio de Horst Christoph Broding y cols. ${ }^{27}$; los panaderos fumadores referían tos y expectoración con más frecuencia que los no fumadores, similares resultados encontraron Joanne Harris-Roberts y cols. ${ }^{30}$, quienes observaron que los panaderos asocian, con una probabilidad 5 veces mayor, el hábito tabáquico con la sensibilización a la harina de trigo o de enzimas en los trabajadores atópicos, considerando el consumo de tabaco un importante factor de riesgo.

En cuanto a las pruebas empleadas para el diagnóstico, J.H. Jacobs y cols. ${ }^{14}$, emplearon la determinación de IgE específica para trigo y alérgenos comunes, espirometría y sintomatología respiratoria, al igual que en el estudio de R. Baatjies y cols. ${ }^{19}$, que emplean también determinación de IgE específica al trigo, centeno y amilasa, espirometría, prick test y test de provocación con metacolina. E. Page y cols.$^{23}$ emplearon IgE específica y obtuvieron que la prevalencia de IgE específica positiva al trigo fue mayor entre los empleados que trabajaron en el grupo de mayor exposición. V. Van Kampen y cols. ${ }^{16}$ evidencian que la prueba de provocación con harinas debe ser considerada de elección con una especificidad del $68 \%$ y $62 \%$ para la harina de trigo y centeno respectivamente y una sensibilidad, para ambos antígenos, del $87 \%$.

La dermatitis de contacto es, en nuestro trabajo de revisión, la dermatosis ocupacional más frecuentemente presentada en los trabajadores de la industria alimentaria, siendo la dermatitis de contacto irritativa (DCI) la dermatosis ocupacional más común.

En el estudio de Yen Loo Lim y Goon Anthony ${ }^{13}$ del 2007 se evidencia una incidencia de dermatitis de contacto ocupacional (DCO) de 62,5 casos por año, con una prevalencia 
de dermatitis de contacto irritativa (DCI) del $62,4 \%$ y de dermatitis de contacto alérgica (DCA) del 37,6\%. Utilizando, como herramientas diagnósticas, las pruebas del parche, con una batería estándar de alérgenos de contacto y alérgenos adicionales que fueran relevantes. La humedad, detergentes, aceites/ grasas y disolventes se evidenciaron como los tres irritantes más comunes de la dermatitis ocupacional.

En otro estudio del $2009^{21}$ sobre profesionales de restaurantes, catering y establecimientos de comida rápida un $10 \%$ de trabajadores presentaron dermatitis de contacto irritativa no se encontró ningún caso de patología de contacto alérgica. A diferencia del estudio anterior, hubo algún caso de urticaria alérgica de contacto para camarón y langosta. Al igual que en el estudio de Y Loo ${ }^{13}$ se determinó la respuesta inmunológica tanto con el prick test como con el patch test.

Se demostró que las tareas en las cuales había un abuso en el lavado de manos (trabajo húmedo) estaban relacionadas con una probabilidad mayor de desarrollar DCI. Otros factores asociados con un riesgo mayor de presentar DCI fueron la atopía y el contacto con el calamar. Otro trabajo dónde se ha estudiado la prevalencia de enfermedades de la piel en relación al contacto con alimentos es el de T. Malkonen y cols. ${ }^{18}$, dónde se analiza la dermatosis laboral y factores de riesgo asociados, recurriendo también, para el diagnóstico, a la prueba del parche y al SPT (skin prick test), como lo hacían S.Teo y cols. En ésta serie de casos la dermatitis de contacto alérgica (DCA), dermatitis de contacto irritativa (DCI), atopía y rinitis y/o conjuntivitis alérgica tenían una prevalencia de $17 \%, 22 \%, 31 \%$ y $14 \%$ respectivamente. Sus resultados evidenciaron que la dermatosis laboral mejoraba en un $17 \%$ de los casos que no cambiaron de puesto de trabajo y en el 34\% de los que sí lo hicieron. La curación en los casos de DCA (27\%) y DCI (23\%) fue similar. Tanto la DCA como la DCI son dos entidades ampliamente descritas en lo referente a patología cutánea relacionada con la industria alimentaria, pero según un estudio de Lotte Vester y cols del año 2012 [28], la dermatitis de contacto proteínica (DCP) es también un trastorno frecuente en las personas que profesionalmente manejan alimentos, y debe ser considerada como una entidad clínica distinta. L Vester estudia la frecuencia de dermatosis ocupacionales de las manos en trabajadores de la industria alimentaria (chef, panaderos, trabajadores en cocina); los resultados mostraron una prevalencia del $57 \%$ de dermatitis de contacto irritativa (DCI), $22 \%$ de dermatitis de contacto proteínica (DCP), 1,8\% alérgica (DCA) y 2,4\% de urticaria de contacto (UC), y observaron que en la dermatitis de contacto proteínica, al igual que en otras dermatosis relacionadas con la alimentación, es importante incluir los alimentos frescos en las pruebas cutáneas de punción (prick test).

Los trabajadores que manipulan productos alimenticios y derivados tienen un mayor riesgo de desarrollar asma ocupacional. La exposición a los alérgenos alimentarios se produce principalmente a través de la inhalación de polvo, vapor, aerosoles y proteínas generados durante el corte, cocinar al vapor, y actividades de lavado, limpieza o secado. Estelle Mounier-Geyssant y cols., en el año 2007, evaluaron en los aprendices de panadería y pastelería la exposición a polvo de harina de trigo, describiendo las tareas que implicaban contacto con harina en el proceso de elaboración y la relacionaron con el desarrollo de asma.

Tina Skjold y cols. ${ }^{12}$ en su estudio de cohorte prospectivo, describieron la incidencia de atopía y síntomas respiratorios entre aprendices de panaderos al inicio de su formación. Se evidenció que la prevalencia de atopía en aprendices de panaderos es la misma que la de la población danesa en general, aunque hubo significativamente más hombres atópicos que mujeres. La atopía es un factor de riesgo para el desarrollo de síntomas respiratorios. Este hallazgo tiene un impacto importante para procedimientos diagnósticos de la alergia ocupacional en panaderos destacando la necesidad de unas pruebas clínicas estandarizadas.

A pesar de que la dermatitis de contacto es una patología frecuente en la industria alimentaria, no hay que olvidar la importancia de las enfermedades respiratorias en éste sector, como es el asma ocupacional. D. Gautrin y cols. ${ }^{[26]}$ en un estudio sobre la relación entre la exposición al cangrejo de las nieves y el asma ocupacional (AO) así como la 
prevalencia de AO y asma ocupacional alérgico (AOA) en plantas de procesamiento de cangrejo de las nieves. Los resultados del trabajo mostraron una prevalencia de AO del 15,8\% y una prevalencia de AOA del 14,9\%; la exposición acumulativa a alérgenos del cangrejo de las nieves está relacionada con la prevalencia de asma ocupacional y asma ocupacional alérgico en una relación dosis-respuesta teniendo en cuenta la atopía, género y tabaquismo. Como en otros trabajos de asma ocupacional, emplearon la determinación de la IgE, prick test, test de provocación con metacolina y espirometría como pruebas diagnósticas.

El lupino es una legumbre utilizada en la industria alimentaria, C. Cambell y cols. ${ }^{10}$ hicieron un estudio en una compañía de procesamiento de alimentos expuestos al lupino, dónde el $21 \%$ de los trabajadores estudiados dieron prick test positivo para lupino. En cuanto a los factores vulnerables, valoraron que el grupo sensible al lupino tuvo tendencia a la atopía y el $64 \%$ de ellos presentaron sintomatología, rinitis y sibilancias.

Solo se encontró un artículo referente a patología sensibilizante de trabajadores en contacto con la soja, fué K. Cummings y cols. ${ }^{22}$ quienes evidenciaron que los trabajadores con IgE específica para la soja tenían 3 veces más probabilidad de presentar asma o sintomatología asmatiforme, esta última se asoció con el trabajo de producción y al aumento del pico de exposición al polvo.

Referente al contacto de los pescaderos con el parásito Anisakis simplex en su entorno laboral, Walter Mazzuco y cols. ${ }^{29}$ evidenciaron que un total del 36,1\% de los pescadores manifestaron síntomas sugerentes de antecedentes alérgicos al parásito. Observaron un aumento significativo de 6 veces en el riesgo de seroconversión a Anisakis simplex, mientras que en los pescaderos/empleados de limpieza de pescado la probabilidad fue 5 veces mayor.

Mohamed F. Jeebhay y cols. ${ }^{24}$, en el año 2010, demostraron que los trabajadores que participan en el procesamiento del pescado (sardina, anchoa) tienen mayor riesgo de estar sensibilizados y desarrollar síntomas de asma relacionado con el trabajo y que el tabaquismo, la atopía y la distribución de género en el trabajo juegan un papel importante en la manifestación de la evolución de las enfermedades alérgicas respiratorias.

En los artículos revisados en nuestro trabajo no se hace referencia en cuanto al impacto de la enfermedad en términos de incapacidad laboral y su tipo, por lo que creemos conveniente seguir investigando sobre este tema.

Podemos concluir que existe una relación evidente entre el desarrollo de patología alérgica respiratoria y cutánea y el trabajo en la industria alimentaria.

La prevalencia de asma ocupacional alérgico (AOA) a alérgenos del cangrejo de las nieves es alta en la Costa Este de Canadá. El sexo femenino, la atopía y el tabaquismo se relacionan con un mayor riesgo de $\mathrm{AO}$ en los trabajadores de estas plantas de procesamiento.

La exposición a la harina de trigo es una de los agentes más frecuentemente estudiado de asma ocupacional.

Dentro de las dermatosis ocupacionales (DO) la dermatitis de contacto irritativa (DCI) sigue siendo más prevalente que la dermatitis de contacto alérgica (DCA), siendo una afectación frecuente en el sector de la restauración.

La dermatitis de contacto proteínica (DCP) es un trastorno frecuente en manipuladores de alimentos y debe considerarse una entidad clínica aparte.

El prick test, las pruebas del parche, la determinación de IgE en suero, la espirometría y el test de provocación con metacolina siguen siendo las técnicas empleadas en el diagnóstico de patología ocupacional sensibilizante, siendo importante incluir alimentos frescos en las pruebas de punción cutánea.

La atopía es un factor de riesgo para el desarrollo de clínica respiratoria en panaderos, y está relacionada con la aparición de DCI. 
El hábito tabáquico, la atopía y el género juegan un papel importante en la evolución de las enfermedades alérgicas respiratorias ocupacionales.

En un futuro, serán necesarios nuevos estudios que ayuden a conocer la verdadera incidencia de la sensibilización alérgica y el asma ocupacional debida al procesamiento del pescado.

\section{REFERENCIAS BIBLIOGRÁFICAS}

1. Gil Hernández F. En: Tratado de Medicina del Trabajo. Aspectos médicos en salud laboral. Vol. II. $2 .^{\mathrm{a}}$ ed. Barcelona: Elsevier Masson; 2012.

2. Real Decreto Legislativo 1/1994, de 20 de junio, por el que se aprueba el texto refundido de la Ley General de la Seguridad Social. Disponible en: http://www.boe.es/buscar/act.php?id=BOE-A-1994-14960.

3. Gómez Martínez M, Zimerman Verdejo M, Alday Figueroa E, Maqueda Blasco J, Ojeda Fernández P. Importancia de la patología laboral sensibilizante, respiratoria y dermatológica en el mundo laboral. MAPFRE MEDICINA 2002; Vol. 13, N. 4 .

4. Peláez Hernández A, Dávila González I.J. En: Tratado de Alergología. Tomo 2. SEAIC. Madrid: Ergon; 2007.

5. Quirce S, Sastre J. New cases of occupational asthma. Curr Opin Allergy Clin Immunol 2011; 11: 80-85.

6. Cartier A. The role of inhalant food allergens in occupational asthma. Curr Allergy Asthma Rep 2010; 10: 349-356.

7. W. Cashman M, A. Reutemann P, Ehrlich A. Contact dermatitis in the Unites States: epidemiology, economic impact, and workplace prevention. Dermatol Clin 2012; 30: 87-98.

8. Real Decreto 1299/2006, de 10 de noviembre, por el que se aprueba el cuadro de enfermedades profesionales en el sistema de la Seguridad Social y se establecen criterios para su notificación y registro. Disponible en: http://www.boe.es/diario_boe/txt.php?id=BOE-A-2006-22169.

9. Primo J. Niveles de evidencia y grados de recomendación (I/II). Enfermedad inflamatoria intestinal al dia 2003; Vol. 2, N. 2 .

10. P. Campbell C, S. Jackson A, R. Johnson A, S. Thomas P, H. Yates D. Occupational sensitization to lupin in the workplace: occupational asthma, rhinitis, and work-aggravated asthma.J Allergy Clin Immunol 2007; Vo1. 191, N. ${ }^{\circ}$ 5: 1133-1139.

11. Mounier-Geyssant E, Barthélemy JF, Mouchot L, Paris C, Zmirou-Navier D. Exponsure of bakery and pastry apprentices to airborne flour dust using $\mathrm{PM}_{25}$ and $\mathrm{PM}{ }_{10}$ personal samples. BMC Public Health 2007; 7: 311.

12. Skjold T, C. Nielsen S, Adolf K, Jürgen Hoffmann H, Dahl R, Sigsgaard T. Allergy in baker冈 apprentices and factors associated to non-participation in a cohort study of allergic sensitization. Int Arch Occup Environ Health. 2007; 80: 458-464.

13. Loo Lim Y, Goon A. Occupational skin diseases in Singapore 2003-2004: an epidemiologic update. Contact Dermatitis 2007; 56: 157-159.

14. Jacobs JH, Meijster T, Meijer E, Suarthana E, Heederik D. Wheat allergen exponsure and the prevalence of work-related sensitization and allergy in bakery workers. Allergy 2008; 63: 1597-1604.

15. Kaatz M, Ladermann R, Stadeler M, Wilhelm Fluhr J, Elsner P, Bauer A. Recruitment strategies for a hand dermatitis prevention programme in the food industry. Contact Dermatitis 2008; 59: 165-170.

16. Van Kampen V, Rabstein S, Sander I, Merget R, Brüning T, Broding HC, Keller C, Müsken H, Overlack A, Schultze-Werninghaus G, Walusiak J, Raulf-Heimsoth M. Prediction of challenge test results by flourspecific IgE and skin prick test in symptomatic baker. Allergy 2008; 63: 897-902.

17. Skjold T, Dahl R, Juhl B, Sigsgaard. The incidence of respiratory symptoms and sensitization in baker apprentices. Eur Respir J 2008; 32: 452-459.

18. Mälkonen T, Jolanki R, Alanko K, Luukonen R, Aalto-Korte K, Lauerma A, Susitaival P. A 6-month follow-up study of 1048 patients diagnosed with an occupational skin diseases. Contact Dermatitis 2009; 61: 261-268.

19. Baatjies R, Lopata AL, Sander I, Raulf-Heimsoth M, Bateman ED, Meijster T, Heederik D, Robins TG, Jeebhay MF. Determinants of asthma phenotypes in supermarket bakery workers. Eur Respir J 2009; 34: 825-833 
20. R.R Heutelbeck A, Junghans C, Esselmann H, Hallier E, G. Schulz T. Exponsure to allergens of different cattle breeds and their relevance in occupational allergy. Int Arch Occup Environ Health 2009; 82: 11231131.

21. Teo S, Teik-Jin Goon A, Hock Siang L, Siok Lin G, Koh D. Occupational dermatoses in restaurant, catering and fast-food outlets in Singapore. Occupational Medicine 2009; 59: 466-471.

22. Cummings KJ, Gaughan DM, Kullman GJ, Beezhold DH, Green BJ, Blachere FM, Bledsoe T, Kreiss K, Cox-Ganser J. Adverse respiratory outcomes associated with occupational exponsure at a soy processing plant. Eur Respir J 2010; 36: 1007-1015.

23. H. Page E, H. Dowell C, A. Mueller C, E. Biagini R, Heederik D. Exponsure to flour dust and sensitization among bakery employees. Am J Ind Med 2010; 53: 1225-1232.

24. F Jeebhay M, G Robins T, E Miller M, Bateman E, Smuts M, Baatjies R, L Lopata A. Occupational allergy and asthma among salt water fish processing workers. Am J Ind Med 2008; 51: 899-910.

25. Meijster T, Tielemans E, Heederik D. Effect of an intervention aimed at reducing the risk of allergic respiratory diseases in bakers: change in flour dust and fungal alpha-amylase levels. Occup Environ Med 2009; 66: 543-549.

26. Gautrin D, Cartier A, Howse D, Horth-Susin L, Jong M, Swanson M, Lehrer S, Fox G, Neis B. Occupational asthma and allergy in snow crab processing in Newfoundland and Labrador. Occup Environ Med 2010; 67: 17-23.

27. Broding HC, Frank P, Hoffmeyer F, Bünger J. Course of occupational asthma depending on the duration of workplace exponsure to allergens - a retrospective cohort study in bakers and farmers. Ann Agric Environ Med 2011; 18: 35-40.

28. Vester L, P. Thyssen J, Menné T, D. Johansen J. Occupational food-related hand dermatoses seen over 10-years period. Contact Dermatitis 2012; 66: 264-270.

29. Mazzucco W, Lacca G, Cusimano R, Provenzani A, Costa A, Di Noto M, Massenti MF, Leto-Barone MS, Di Lorenzo G, Vitale F. Prevalence of sensitization to Anisakis simplex among professionally exposed population in Sicily. Archives of Environmental and Occupational Health 2012; 67, N. 2.

30. Harris-Roberts J, Robinson E, C. Waterhouse J, G. Billings C, R. Proctor A, Stocks-Greaves M, Rahman S, Evans G, Garrod A, D. Curran A, Fishwick D. Sensitization to wheat flour and enzymes and association respiratory symptoms in British bakers. Am J Ind Med 2009; 52: 133-140.

31. Rémen T, Coevoet V, Acouetey DS, Guéant JL, Guéant-Rodriguez RM, Paris C, Zmirou-Navier D. Early incidence of occupational asthma among young baker, pastry-makers and hairdressers: desing of a retrospective cohort study. BMC Public Health 2010; 10:

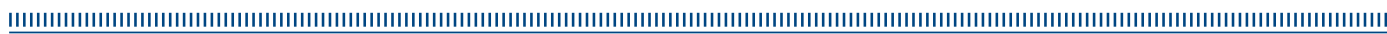

